\title{
Article \\ JAK-STAT Pathway Inhibition Partially Restores Intestinal Homeostasis in Hdac1- and Hdac2-Intestinal Epithelial Cell-Deficient Mice
}

\author{
Alexis Gonneaud *, Naomie Turgeon, Francois-Michel Boisvert, Francois Boudreau and Claude Asselin
}

check for updates

Citation: Gonneaud, A.; Turgeon, N.; Boisvert, F.-M.; Boudreau, F.; Asselin, C. JAK-STAT Pathway Inhibition Partially Restores Intestinal Homeostasis in Hdac1- and Hdac2-Intestinal Epithelial Cell-Deficient Mice. Cells 2021, 10, 224. https://doi.org/10.3390/ cells10020224

Received: 23 November 2020

Accepted: 19 January 2021

Published: 23 January 2021

Publisher's Note: MDPI stays neutral with regard to jurisdictional claims in published maps and institutional affiliations.

Copyright: (c) 2021 by the authors. Licensee MDPI, Basel, Switzerland. This article is an open access article distributed under the terms and conditions of the Creative Commons Attribution (CC BY) license (https:// creativecommons.org/licenses/by/ $4.0 /)$.
Département D'immunologie et Biologie Cellulaire, Pavillon de Recherche Appliquée Sur le Cancer, Faculté de Médecine et Des Sciences de la Santé, Université de Sherbrooke, Sherbrooke, QC J1E 4K8, Canada; Naomie.Turgeon@USherbrooke.ca (N.T.); Francois.Michel.Boisvert@USherbrooke.ca (F.-M.B.); Francois.Boudreau@USherbrooke.ca (F.B.); Claude.Asselin@USherbrooke.ca (C.A.)

* Correspondence: Alexis.Gonneaud@USherbrooke.ca; Tel.: +1-(819)-821-8000 (ext. 75276); Fax: +1-(819)-820-6831

Abstract: We have previously reported that histone deacetylase epigenetic regulator Hdac1 and $\mathrm{Hdac} 2$ deletion in intestinal epithelial cells (IEC) disrupts mucosal tissue architecture and barrier, causing chronic inflammation. In this study, proteome and transcriptome analysis revealed the importance of signaling pathways induced upon genetic IEC-Hdac1 and Hdac2 deletion. Indeed, Gene Ontology biological process analysis of enriched deficient IEC RNA and proteins identified common pathways, including lipid metabolic and oxidation-reduction process, cell adhesion, and antigen processing and presentation, related to immune responses, correlating with dysregulation of major histocompatibility complex (MHC) class II genes. Top upstream regulators included regulators associated with environmental sensing pathways to xenobiotics, microbial and diet-derived ligands, and endogenous metabolites. Proteome analysis revealed mTOR signaling IEC-specific defects. In addition to mTOR, the STAT and Notch pathways were dysregulated specifically in jejunal IEC. To determine the impact of pathway dysregulation on mutant jejunum alterations, we treated mutant mice with Tofacitinib, a JAK inhibitor. Treatment with the inhibitor partially corrected proliferation and tight junction defects, as well as niche stabilization by increasing Paneth cell numbers. Thus, IEC-specific histone deacetylases 1 (HDAC1) and 2 (HDAC2) support intestinal homeostasis by regulating survival and translation processes, as well as differentiation and metabolic pathways. HDAC1 and HDAC2 may play an important role in the regulation of IEC-specific inflammatory responses by controlling, directly or indirectly, the JAK/STAT pathway. IEC-specific JAK/STAT pathway deregulation may be, at least in part, responsible for intestinal homeostasis disruption in mutant mice.

Keywords: intestinal epithelial cell; HDAC; proteome; transcriptome; organoid; STAT3; tofacitinib

\section{Introduction}

The intestinal epithelium interfaces the luminal microbiota and the mucosal immune system in a perpetual vigil, acting as a sensor of, and responder to, their respective signals [1,2]. The intestinal epithelium is unceasingly regenerated from crypt-residing intestinal stem cells (ISC) which produce transit-amplifying progenitor cells [3]. Upon their migration along the crypt-villus axis, these cells adopt differentiation programs to produce enterocyte and secretory cell lineages with complementary roles in establishing selective barrier function. Intestinal epithelial differentiated cells include enterocytes, with essential roles in nutrient absorption and digestion, in the establishment of the intestinal selective barrier through tight junctions and anti-bacterial gene expression, as well as immunoglobulin transport [4]. Goblet cells participate in barrier formation by secreting mucins as well as several anti-microbial proteins, and by acting as a conduit delivering luminal products 
to mucosal antigen-presenting cells [5]. Paneth cells, in addition to carving microbiota configuration and protecting the epithelium through secretion of anti-microbial proteins, regulate the stem cell niche environment [6]. Different types of hormone-secreting enteroendocrine cells display many roles, from systemic glucose homeostasis to mucosal immune responses $[7,8]$. Both ISC renewal and cell lineage specification depend on the coordinated action of various signaling pathways, including the Wnt, Notch and BMP pathways [3]. However, environmental as well as immune modifications along with genetic predispositions may overturn this delicate balance, leading to improper innate and adaptive intestinal inflammatory reactions, as observed in inflammatory bowel diseases (IBD) [9].

In recent years, a potential role of epigenetics in IBD, as receiver and transmitter of environmental changes, has emerged [10]. Indeed, some studies have uncovered IBD genetic susceptibility loci with epigenetic signatures associated with regulatory regions $[11,12]$. Lysine acetylation is one epigenetic mark controlling gene expression. While the acetyltransferase-dependent transfer of acetyl groups from acetyl-CoA on histones and other proteins is usually associated with gene expression, removal of the acetyl group by HDAC leads to gene repression. Acetylation is regulated in part by compartment-specific cellular acetyl-CoA levels responding to different environmentally induced metabolic changes [13]. In addition, both endogenous metabolites, such as $\beta$-hydroxybutyrate [14], as well as exogenous metabolites, such as the microbiota-produced butyrate [15], alter histone acetylation by inhibiting HDAC activity. Among the four HDAC classes, class I deacetylase HDAC1 and HDAC2, as part of multiprotein complexes, regulate gene expression as well as DNA replication and DNA repair [16,17]. While murine Hdac1 deletion is developmentally lethal, Hdac2 deletion results in heart defect-related death after birth. In contrast, most tissue-specific Hdac1 and Hdac2 individual or compound deletions have revealed both compensatory and distinct roles in tissue homeostasis and differentiation. Indeed, while tissue-specific $H d a c 1$ or $H d a c 2$ deficiencies lead to modest tissue alterations, deletion of both genes disrupts proliferation and differentiation in most tissues [16,17]. In the intestine, we have shown that villin-Cre-mediated Hdac1 and Hdac2 deletion disrupts IEC barrier function and differentiation, leading to chronic colonic inflammation [18]. Of note, intestinal tissue disruption in mutant mice is accompanied by simultaneous activation of the enterocyte-secretory cell lineage regulating Notch pathway, of the inflammation and mucosal healing supporting STAT3 pathway [19], and of the growth and metabolismregulating mTOR pathway [20].

In this report, we used IEC-specific Hdac1 and Hdac2 deletion to determine the intrinsic jejunal IEC responses dependent upon HDAC1 and HDAC2, by transcriptome and proteome analysis. We first confirmed the importance of HDAC1 and HDAC2 for organoid growth, with both in vivo and inducible Hdac1 and Hdac2 deletion models. Omics data revealed that HDAC1 and $\mathrm{HDAC} 2$ control metabolic and environmental sensing pathways, and that IEC-specific deletion leads to improper STAT3, Notch and mTOR activation in IEC. We then assessed the importance of the STAT pathway in regulating both mucosal inflammation as well as disrupted Notch and mTOR pathways, by histological and immunostaining in mutant mice treated with a JAK/STAT pathway inhibitor, Tofacitinib. Our results show that the mutant phenotype is dependent upon STAT activation, as Tofacitinib treatment partially restores mucosal homeostatic responses, including proliferation and Paneth cell numbers. Thus, IEC-specific HDAC1 and HDAC2 support intestinal homeostasis by regulating survival and translation processes, as well as differentiation and metabolic pathways. They play an important role in the regulation of inflammatory responses by controlling, directly or indirectly, the JAK/STAT pathway. IEC-specific JAK/STAT pathway deregulation may be, at least in part, responsible for mucosal intestinal homeostatic disruption in mutant mice. 


\section{Material and Methods}

\subsection{Mice}

Hdac1 and Hdac2 floxed mice [21] were crossed either with villin-Cre transgenic mice [22] to ensure IEC-specific $H d a c 1$ and $H d a c 2$ deletion, or with villin-Cre ${ }^{\mathrm{ER}}$ transgenic mice [23], to obtain Tamoxifen-inducible IEC-specific Hdac1 and Hdac2 deletion, in a C57BL/6J X 129SV X CD1 background. Experiments were approved by the Institutional Animal Review Committee of the Université de Sherbrooke (protocol 360-14B), according to relevant guidelines and regulations. Genotypes were determined by using selected primers to amplify genomic DNA purified with the Spin Doctor genomic DNA kit (Gerard Biotech, Oxford, OH, USA), as before [18,24,25]. Three- to four-month-old wild-type and IEC-specific villin-Cre $\mathrm{Hdac1}^{-/-} ; \mathrm{Hdac} 2^{-/-}$mice were injected intraperitoneally with $30 \mathrm{mg} / \mathrm{kg}$ of the pan-JAK inhibitor Tofacitinib (Cayman Chemical Company, Ann Arbor, MI, USA) [26], or with $10 \mathrm{mg} / \mathrm{kg}$ of the Notch inhibitor DBZ or Dimethyl Sulfoxide (DMSO), for five days ( $n=3$ for each group). To assess proliferation, mice were injected intraperitoneally with $10 \mathrm{~mL} / \mathrm{kg}$ of bromodeoxyuridine (BrdU, Life Technologies, Grand Island, NY, USA) on day 6 , for $2 \mathrm{~h}$. Mice were killed on the sixth day.

\subsection{Enteroid Cultures}

Jejunal crypts from three- to four-month-old wild-type and villin-Cre $\mathrm{Hdac1}^{-/-}$; $H d a c 2^{-/-}$mice were fractionated by EDTA treatment, embedded in Matrigel and grown in ENR medium for five days, according to published methods $[27,28]$, and as we have done before [29,30]. Jejunal crypts from control and $\mathrm{Hdac1}^{-/-} ; \mathrm{Hdac}^{-/-}$villin-Cre ${ }^{\mathrm{ER}}$ mice were isolated as above and treated with $0.5 \mu \mathrm{M}$ of 4-hydroxy Tamoxifen (OHT)(Cayman Chemical Company) or DMSO for five days. Enteroids were passaged if needed. Enteroid phenotypes were assessed by microscopic image analysis with a Leica DC300 microscope (Leica Microsystems Inc., Richmond Hill, ON, Canada.) or a Cell Discoverer 7 microscope (magnification: $10 \times)$ (Zeiss, North York, ON, Canada).

\subsection{RNA Isolation and Quantitative Real-Time PCR ( $q P C R$ )}

Jejunal IEC from three-month-old wild-type and villin-Cre $\mathrm{Hdac1}^{-/-} ; \mathrm{Hdac2}^{-/-}$mice were enriched by EDTA treatment. Jejunal IEC RNAs were isolated with the Rneasy kit (Qiagen, Montréal, QC, Canada). RNAs were quantified with a NanoDrop ND-1000 spectrophotometer (Thermo Fisher Scientific, Saint-Laurent, QC, Canada). cDNAs were synthesized from one $\mu \mathrm{g}$ RNA, with oligo dT15 primers and the Superscript II reverse transcriptase (Life Technologies Inc.). qPCR analysis was performed from $10 \mathrm{ng}$ of cDNA, with the Brilliant III Ultra-fast SYBR Green qPCR Master Mix (Agilent Technologies, SaintLaurent, QC, Canada) and gene-specific upstream and downstream oligonucleotides for stem cell marker Lgr5, secretory cell differentiation marker Atoh1, goblet cell marker Muc2, Tff3 and Zg16, Paneth cell marker Cryptdin, Lys2 and Defa24, enterocyte marker Sis, Slc15a1, Alpi and Fabp2, enteroendocrine cell marker $C h g A$, proliferation marker Ccnd1, MHC II genes Cd74, H2Aa, H2Ab1, H2Eb1, H2Dma, H2Dmb1, H2D and Ciita, as well as Reg3b, Reg3g and Jag2, and the Pbgd loading control (Supplementary Table S1 for a list of primers). cDNA amplification was performed with a 10 min cycle at $95^{\circ} \mathrm{C}$, followed by 40 cycles of $10 \mathrm{~s}$ at $95^{\circ} \mathrm{C}, 10 \mathrm{~s}$ at $60^{\circ} \mathrm{C}$ and $20 \mathrm{~s}$ at $72{ }^{\circ} \mathrm{C}$, on a Corbett RotorGene instrument (Qiagen/Corbett Research, Montréal, QC, Canada). Relative RNA amounts were determined by comparing to Pbgd amplification $(n=4-5)$.

\subsection{RNA-Seq Analysis}

Jejunal IEC from three-month-old wild-type and villin-Cre $\mathrm{Hdac1}^{-/-} ; \mathrm{Hdac2}{ }^{-/-}$mice were enriched by EDTA treatment. Jejunal IEC RNAs were isolated with the ToTALLY RNA $^{\mathrm{TM}}$ (Thermo Fisher Scientific) and Rneasy kits (Qiagen) $(n=3)$. Samples with RNA integrity number over 6.5 were selected with a 2100 Bioanalyser (Agilent Technologies). cDNA libraries were prepared and the transcriptome was determined with the Illumina HiSeq4000 PE100 sequencing system (Illumina, San Diego, CA, USA) at the McGill Uni- 
versity and Génome Québec Innovation Center. Sequences were aligned with the Star 2.4.0.1 software package based on the genome reference Mus_musculus:GRCm38. Differentially expressed genes were identified with DESeq adjusted $p$-value $\leq 0.05$ [31]. Two-fold increased or decreased transcripts between control and $\mathrm{Hdac1}^{-/-} ; \mathrm{Hdac}^{-/-}$IEC were selected for additional bioinformatics analysis. RNA-Seq data have been deposited in the Gene Expression Omnibus database (GSE158522).

\subsection{Proteome Analysis}

Jejunal IEC from three-month-old wild-type and villin-Cre $\mathrm{Hdac1}^{-/-} ; \mathrm{Hdac}^{-/-}$mice were enriched by EDTA treatment. IEC were lysed in TEAB buffer (100 mM triethylammonium bicarbonate, $10 \%$ SDS $)(n=3)$. Amounts of $50 \mu \mathrm{g}$ of proteins were reduced with tris(2-carboxyethyl)phosphine for one hour at $55{ }^{\circ} \mathrm{C}$, and alkylated with $375 \mathrm{mM}$ iodoacetamide for $30 \mathrm{~min}$ in the dark. Proteins were precipitated with acetone for $4 \mathrm{~h}$ at $-20^{\circ} \mathrm{C}$, and suspended in TEAB buffer and trypsin for overnight digestion at $37^{\circ} \mathrm{C}$. After digestion, peptides were labeled with isobaric chemical Tags of 126 to $128 \mathrm{Da}$ (controls) and 129 to $131 \mathrm{Da}$ (mutants), for one h at room temperature (Tandem Mass Tag Reagents (TMT), Thermo Fisher Scientific). The reaction was stopped by adding $5 \%$ hydroxylamine for $15 \mathrm{~min}$. Labeled peptides were mixed and washed on C18 columns, according to the manufacturer's instructions. Samples were then separated by liquid phase chromatography and MS/MS mass spectrometry. Peptides were separated with an ultimate U3000 nanoflow LC-system (Dionex Corporation, Sunnyvale, CA, USA). The HPLC system was coupled to an OrbiTrap Q Exactive, via an EasySpray source. The following parameters were used, as suggested by the manufacturer. For MS: Resolving power (FWHM at m/z 200), 70,000; AGC target, $3 \times 10^{6}$; Maximum injection time (ms), 50; Scan range (m/z), 375-1400. For MS/MS: Resolving power (FWHM at m/z 200), 35,000; AGC target, $1 \times 10^{5}$; Maximum injection time (ms), 100; Isolation width (Th), 0.7 or 1.2; Normalized collision energy (NCE), 32 (Thermo Fisher Scientific). Data were acquired with the Excalibur software. Protein identification, as well as TMT-labeled peptide quantitation, were performed with the MaxQuant version 1.5.2.8 software [32] and the Uniprot mouse protein database, as we have done before [29]. The false discovery rate (FDR) was adjusted to $5 \%$. Then, $50 \%$ increased or decreased proteins between control and $\mathrm{Hdac1}^{-/-} ; \mathrm{Hdac2}^{-/-}$IEC were selected for additional bioinformatics analysis. Mass spectrometry proteomic data were deposited to the ProteomeXchange Consortium through the PRIDE partner repository with the dataset identifier PXD (PXD022558) (http:/ / proteomecentral.proteomexchange.org PRIDE (EMBL-EBI, Cambridge, UK).

\subsection{Bioinformatics Analysis}

Transcriptome and proteome data were used to classify genes according to Gene Ontology with the Database for Annotation, Visualization and Integrated Discovery software (DAVID 2.0) [33] and the Ingenuity Pathway Analysis software (IPA, Qiagen). Pathway activation (Upstream Regulator Analysis (URA), z-score) was predicted from the variations between samples and the altered biological processes [34].

\subsection{Histological Analysis, Immunofluorescence and Immunocytochemistry}

Wild-type and $\mathrm{Hdac1}^{-/-} ; \mathrm{Hdac}^{-/-}$villin-Cre ${ }^{\mathrm{ER}}$ enteroids treated with or without $0.5 \mu \mathrm{M}$ of 4-hydroxy Tamoxifen for five days were used $(n=3)$. Paraformaldehyde-fixed enteroids were mixed with Histogel (Thermo Fisher Scientific) before paraffin inclusion. Nuclei were stained with DAPI when needed. To assess DNA damage by immunofluorescence, paraffin-embedded enteroid sections were labeled with a primary rabbit antibody against phospho-histone $\gamma$ H2A.X (sc-101696) (1:500, Santa Cruz Biotechnology, Santa Cruz, $\mathrm{CA}, \mathrm{USA}$ ) and $\mathrm{F}\left(\mathrm{ab}^{\prime}\right)$ rabbit IgG ( $\mathrm{H}+\mathrm{L}$ ) (Alexa Fluor 568) preadsorbed secondary antibodies (Abcam, Cambridge, MA, USA), as previously done [30].

Wild-type and villin-Cre $\mathrm{Hdac1}^{-/-}$; Hdac2 ${ }^{-/-}$jejuna, from mice treated with or without Tofacitinib, were fixed in $4 \%$ paraformaldehyde and enclosed in paraffin. Four 
$\mu \mathrm{m}$-sections were stained with hematoxylin and eosin for histological analysis, and with Best's Carmine for Paneth cell staining. Proliferation was determined by staining with fluorescein-conjugated mouse antibody against bromodeoxyuridine (BrdU) (1:50, BMC 9318, Roche Diagnostics, Laval, QC, Canada). BrdU positive nuclei and Paneth cells were counted with Cell Profiler 3.15 [35]. Sections were rehydrated with graded ethanol series containing 100, 95, 80 and 70\% xylene, and then boiled for 12 min in $10 \mathrm{mM}$ citric acid for immunofluorescence, or boiled for $20 \mathrm{~min}$ in a $10 \mathrm{mM}$ Tris pH 9.0, EDTA 1 $\mathrm{mM}, 0.05 \%$ Tween-20 solution for immunocytochemistry. Sections were blocked in a PBS solution containing $0.1 \%$ BSA and $0.2 \%$ Triton X-100 for $45 \mathrm{~min}$. For immunofluorescence experiments, sections were incubated with a rabbit antibody against Claudin-3 (341700) (1:200, Invitrogen) or a goat antibody against lysozyme (sc-27958) (1:500, Santa Cruz Biotechnology). Primary antibodies were recognized with secondary Alexa Fluor 568 goat anti-rabbit IgG $(\mathrm{H}+\mathrm{L})$ or Alexa Fluor 555 donkey anti-goat IgG $(\mathrm{H}+\mathrm{L})$ (Life Technologies). For immunocytochemistry experiments, sections were incubated with rabbit antibodies against phospho-S6 ribosomal protein (\#2211) (1:500, Cell Signaling, Whitby, ON, Canada), against Stat3 (\#12640) (1:200, Cell Signaling) and against the T-cell marker CD3 (A0452) (1:500, Dako Canada, Burlington, ON, Canada), followed by labeling with EnVision + System-HRP (Dako Canada). Information about antibodies is included in Supplementary Table S2.

\subsection{Western Blot Analysis}

Jejunal IEC from three-month-old wild-type and villin-Cre $\mathrm{Hdac1}^{-/-} ; \mathrm{Hdac2}{ }^{-/-}$mice were enriched by EDTA treatment. IEC were lysed in $1 \mathrm{X}$ Laemmli buffer $(62.5 \mathrm{mM}$ Tris- $\mathrm{HCl} \mathrm{pH}$ 6.8, 2\% SDS, 10\% glycerol) supplemented with protease and phosphatase inhibitors. Protein concentrations were determined with the Pierce BCA Protein Assay kit (Therrmo Fisher Scientific). Amounts of $15 \mu \mathrm{g}$ of total proteins were separated on 4-12\% SDS-polyacrylamide gels, and transferred on PVDF membranes (Roche Molecular Biochemicals). Membranes were incubated $1 \mathrm{~h}$ at room temperature or overnight at $4{ }^{\circ} \mathrm{C}$ with primary antibodies including rabbit anti-phospho-Stat3 (\#9145, Cell Signaling), rabbit anti-Stat3 (\#12640, Cell Signaling), rabbit anti-phospho-p38 (\#4511, Cell Signaling), rabbit anti-claudin 3 (341700, Invitrogen), rabbit anti-cleaved Notch (\#4147, Cell Signaling), rabbit anti-phospho-S6 (\#4858, Cell Signaling) and GAPDH (\#2118, Cell Signaling). Primary antibodies were recognized with secondary goat anti-rabbit antibodies (Life Technologies) before immune complex detection with Amersham ECL ${ }^{\mathrm{TM}}$ Western blotting detection reagents (GE Healthcare, Mississauga, ON, Canada).

\subsection{Statistical Analysis}

Data are expressed as the mean \pm SEM. Groups were compared by Student's $t$-test (unpaired), or one-way ANOVA with Tukey multiple comparison test.

\section{Results and Discussion}

We have previously observed that IEC-specific dual deletion of Hdac1 and Hdac2 led to IEC differentiation and proliferation alterations, as well as chronic inflammation in the colon [18]. To determine whether HDAC1 and HDAC2 are both needed for IEC growth and survival, we generated enteroid cultures from villin-Cre dual $H d a c 1^{-/-} ; H d a c 2^{-/-}$murine crypts. After five days of culture, growth was stopped in all enteroids, with the absence of budding ( $n=3$, Supplementary Figure S1). Attempts to passage the enteroids were unsuccessful. This suggests that during enteroid growth, deletion of the remaining Hdacl or Hdac2 allele occurs, leading to cell growth inhibition and death. We then produced enteroids from crypts isolated from villin-Cre ${ }^{\mathrm{ER}}$ dual $\mathrm{Hdac1}^{-/-} ; \mathrm{Hdac}^{-/-}$mice. As opposed to control enteroids, villin-Cre ${ }^{E R}$ enteroids treated for 5 days with Tamoxifen displayed enteroid structure alterations, reduction in budding and growth arrest (Figure 1A), as well as increased phospho- $\gamma-\mathrm{H} 2 \mathrm{AX}$ staining, a marker of DNA damage (Figure 1B). Thus,

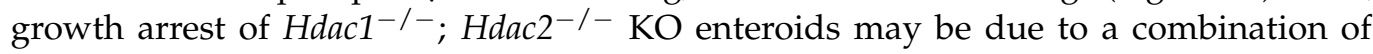


chromatin destabilization and accumulation of DNA damage, which may lead to organoid death. Indeed, HDAC1 and HDAC2 are both needed to regulate DNA repair and the double-strand break-dependent DNA damage response [36]. In agreement with this, we have previously observed increased phospho- $\gamma-\mathrm{H} 2 \mathrm{AX}$ staining in Hdac1- or Hdac2depleted enteroids, suggesting again augmented sensitivity to DNA damage upon DNA replication [30]. Our results, with in vivo and inducible deletion organoid models, confirm those of Zimberlin et al. [37], that both Hdac1 and Hdac2 are necessary for organoid growth.

The question remains about the difference between the death of organoids deleted for HDAC1 and HDAC2 and living mutant mice; which pathways are implicated in maintaining mutant mice alive? We have previously shown by microarray analysis of total IEC-specific Hdac1 and Hdac2 deleted colonic RNAs the presence of chronic intestinal inflammation [18]. To determine the IEC-intrinsic effect of Hdac deletion in the jejunum of mutant mice, we verified the global transcriptome and proteome of EDTA-enriched jejunal cells from wild-type and villin-Cre $H d a c 1^{-/-} ; H_{d a c} 2^{-/-}$mice. RNA-Seq analysis identified 1904 genes with increased expression (more than 2-fold) and 1682 genes with decreased expression (less than 0.5 -fold) in dual Hdac-deficient jejunal cells (DESeq adjusted $p$-value $\leq 0.05$ ), representing respectively $9.7 \%$ and $8.6 \%$ of total identified genes (Supplementary Table S3). Mass spectrometry proteomic analysis of differentially labeled TMT proteins revealed 332 proteins increased (more than 1.5-fold) and 423 proteins decreased (less than 0.75 -fold) in dual Hdac-deficient jejunal cells (FDR 5\%), representing respectively $10.3 \%$ and $13 \%$ of the total detected proteins (Supplementary Table S4).

Among the top canonical pathways, retinol biosynthesis, melatonin and nicotine degradation pathways were shared between the transcriptome and the proteome (Figures $2 \mathrm{~A}$ and $3 \mathrm{~A}$ ). Data analysis revealed estrogen biosynthesis, FXR/RXR and LXR/RXR activation as top canonical pathways for the transcriptome (Figure 2A), and EIF2 signaling, LPS/IL-1 mediated inhibition of RXR function and antigen presentation pathway for the proteome (Figure 3A). Activation of nuclear receptors such as FXR, is related to deregulation of lipid metabolism pathways, including oxidation of fatty acids [38], that may provide energy for IEC as well increased production of the acetyl donor, acetyl-CoA, the major regulator of histone acetylation. EIF2 signaling activation observed in the proteome analysis, but not the transcriptome analysis, confirms mTOR pathway activation associated with increased small intestine lengthening, observed in villin-Cre Hdac1 ${ }^{-/-} ; \mathrm{Hdac}^{-/-}$mice [18]. Gene Ontology analysis with DAVID identified common proteome and transcriptome biological processes, such as lipid metabolic process, metabolic process, cell adhesion, oxidationreduction process and antigen processing and presentation, related to immune responses. It was observed that after HDAC inhibition in dendritic cells results in STAT3-regulated gene expression modifications. Downregulated STAT3-dependent targets are involved in immune effector processes and antigen processing/presentation, as we observed here. This suggests a direct interaction between HDAC activity and STAT3-targeted gene regulation [39]. Again, most deregulated pathways following Hdac1 and Hdac2 loss in IEC involve metabolic processes associated with acetyl-CoA production pathways. GO analysis identified specific transcriptome-associated biological processes, such as negative regulation of extrinsic apoptosis, multicellular organism development, epithelial cell differentiation and transport, and specific proteome-associated biological processes related to translation, defense response to bacteria and chromatin regulation (Figures $2 \mathrm{~B}$ and $3 \mathrm{~B}$ ). Disease and biological functions sorted by z-score highlighted downregulation of lipid-related functions at both RNA and protein levels (Supplementary Table S5). Top upstream regulators common to mutant transcriptome and proteome included CFTR, PPARA with associated regulators (ciprofibrate and ACOX), PPARG, HNF4A and IL10RA, as determined by IPA analysis (Supplementary Table S6). Thus, HDAC-dependent epigenetic modifications play an important role in controlling intrinsic and extrinsic pathways of intestinal homeostasis. Indeed, Hdac deletion results in consistent alterations in environmental sensing pathways to xenobiotics, microbial and diet-derived ligands, as well as endogenous cell metabolites. 
A

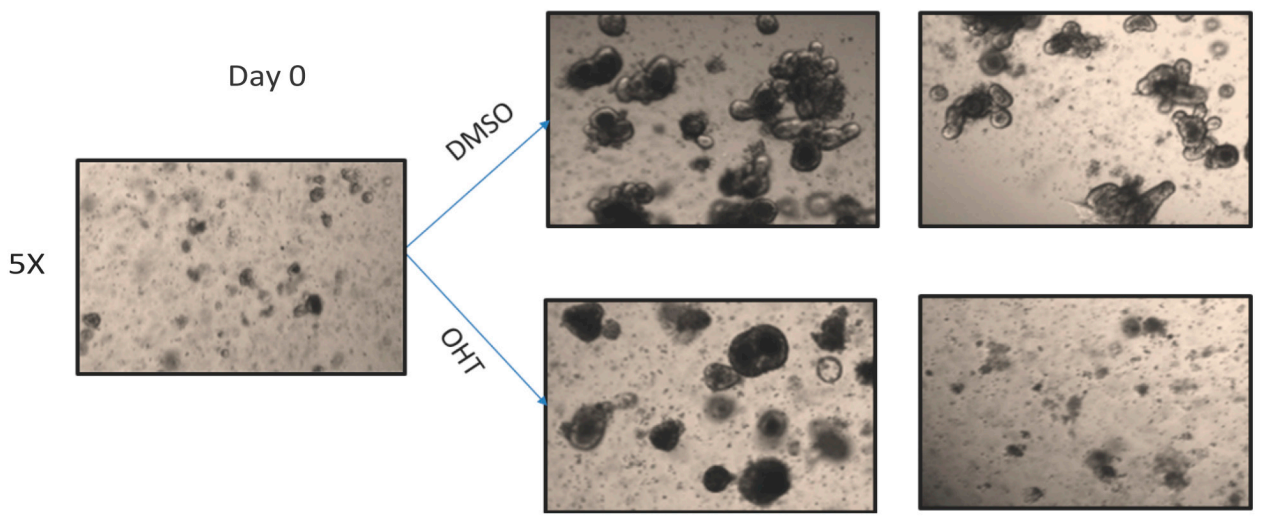

B Merging of nuclear (blue) and $\gamma-\mathrm{H} 2 \mathrm{AX}$ (yellow) staining

120 h DMSO

$10 x$
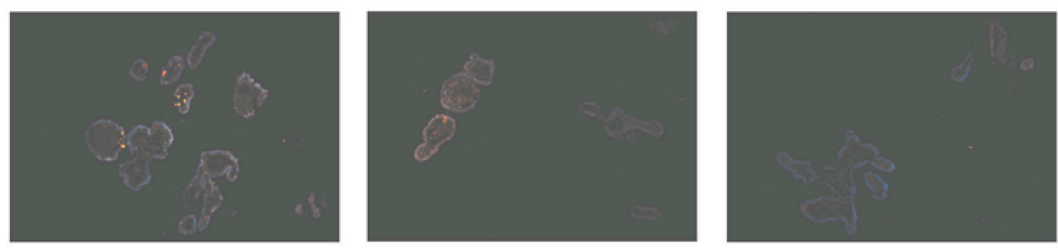

$20 x$
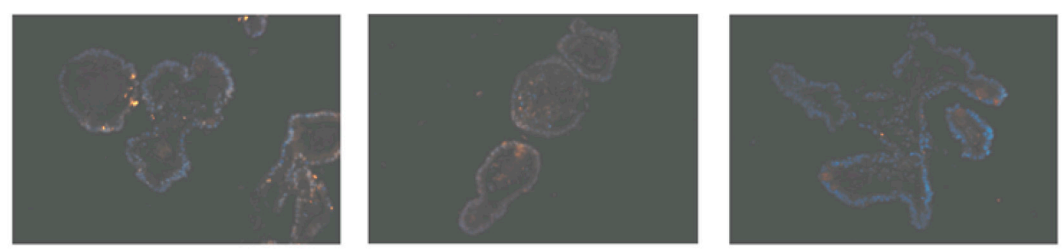

$120 \mathrm{~h} \mathrm{OHT}$
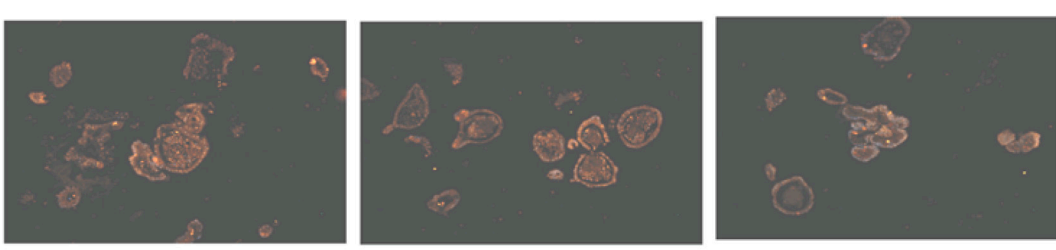

$10 x$
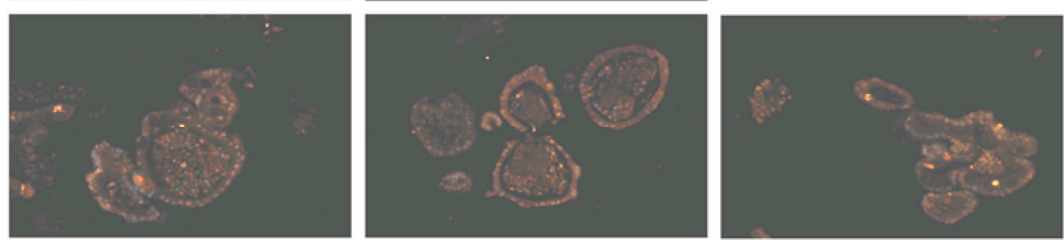

Figure 1. Enteroid growth is disrupted after inducible Hdac1 and Hdac2 deletion. (A) Representative micrographs of 5-day DMSO or tamoxifen (OHT) treated control or $\mathrm{Hdac1}^{-/-} ; \mathrm{Hdac}^{-/-}$villin-Cre ${ }^{\mathrm{ER}}$ enteroids $(n=3)$ and three days after passage. Magnification: $5 \times$. (B) Representative images of merged 5-day DMSO or tamoxifen (OHT) treated control or $\mathrm{Hdac1}^{-/-} ; \mathrm{Hdac}^{-/-}$villin-Cre ${ }^{\mathrm{ER}}$ enteroids stained with an antibody against phospho- $\gamma-\mathrm{H} 2 \mathrm{AX}$ and with DAPI for nuclear staining $(n=3)$. Magnification: $10 \times, 20 \times$. 
A Top canonical pathways for increased or decreased transcripts identified by IPA analysis

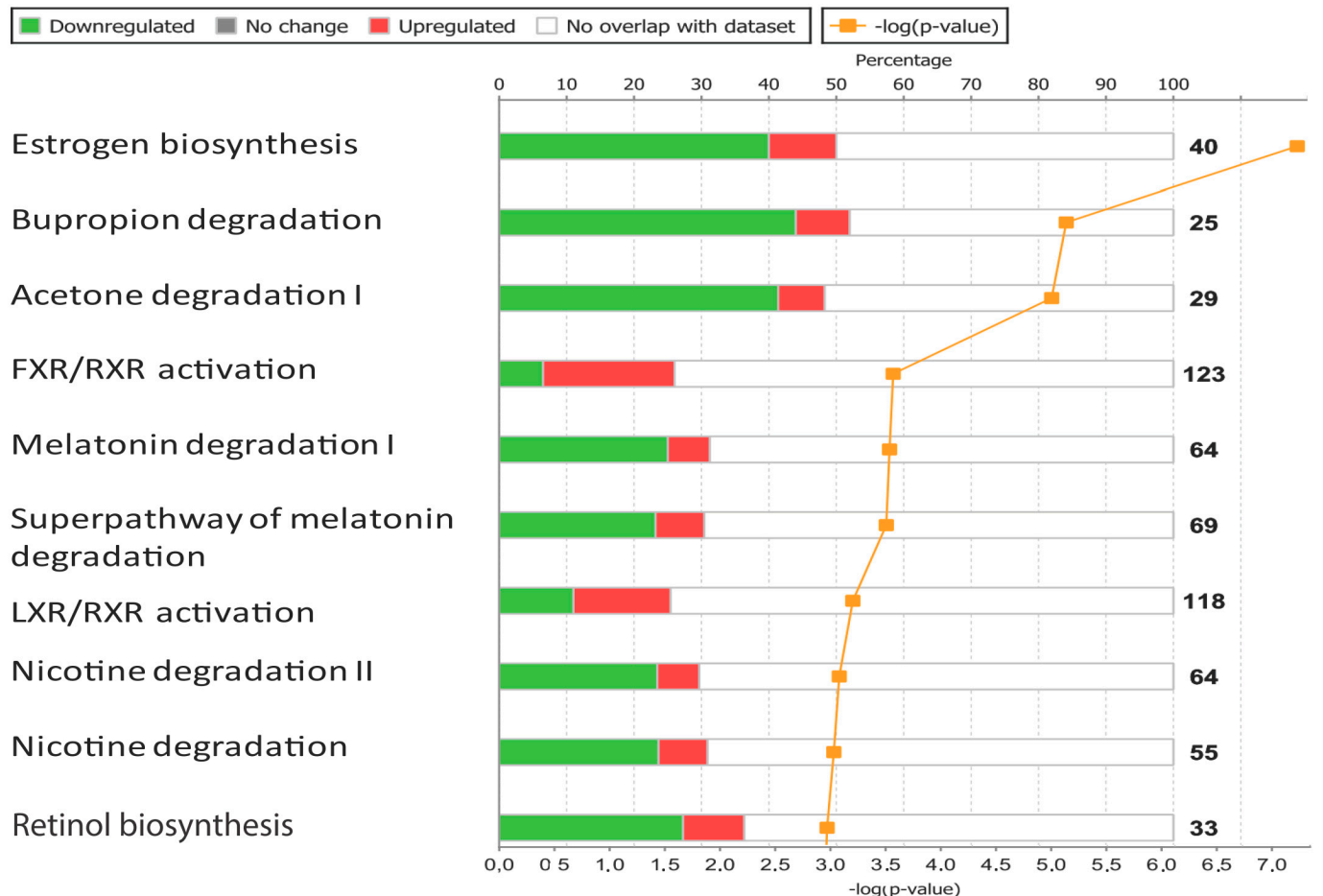

B Gene ontology analysis of biological processes for increased or decreased transcripts

\begin{tabular}{|c|c|c|c|}
\hline \multicolumn{4}{|c|}{ GOTERM_BP_DIRECT of IEC-deleted Hdac1/2 transcripts } \\
\hline Transcripts increased by $>2$ & P-value & Transcripts decreased by $<0.25$ & P-value \\
\hline negative regulation of extrinsic apoptotic signaling pathway & $1.2 \times 10^{-5}$ & oxidation-reduction process & $3.2 \times 10^{-7}$ \\
\hline lipid metabolic process & $2.4 \times 10^{-5}$ & transport & $2.4 \times 10^{-5}$ \\
\hline multicellular organism development & $4.2 \times 10^{-5}$ & metabolic process & $1.8 \times 10^{-4}$ \\
\hline positive regulation of peptide hormone secretion & $6.3 \times 10^{-5}$ & epithelial cell differentiation & $5.6 \times 10^{-4}$ \\
\hline iron ion homeostasis & $8.5 \times 10^{-5}$ & antigen processing and presentation of peptide antigen via MHC class I & $5.8 \times 10^{-4}$ \\
\hline rRNA processing & $1.8 \times 10^{-4}$ & protein deacetylation & $8.0 \times 10^{-4}$ \\
\hline brain development & $3.0 \times 10^{-4}$ & lipid metabolic process & $8.3 \times 10^{-4}$ \\
\hline response to hypoxia & $3.7 \times 10^{-4}$ & steroid metabolic process & $1.7 \times 10^{-3}$ \\
\hline cell differentiation & $3.9 \times 10^{-4}$ & regulation of systemic arterial blood pressure by renin-angiotensin & $2.9 \times 10^{-3}$ \\
\hline cholesterol homeostasis & $4.2 \times 10^{-4}$ & carnitine transport & $2.9 \times 10^{-3}$ \\
\hline cellular response to calcium ion & $8.9 \times 10^{-4}$ & nitrogen compound metabolic process & $3.0 \times 10^{-3}$ \\
\hline metabolic process & $9.9 \times 10^{-4}$ & cholesterol homeostasis & $3.5 \times 10^{-3}$ \\
\hline steroid metabolic process & $1.0 \times 10^{-3}$ & response to drug & $3.6 \times 10^{-3}$ \\
\hline actin cytoskeleton organization & $1.0 \times 10^{-3}$ & aging & $3.8 \times 10^{-3}$ \\
\hline extracellular matrix disassembly & $1.3 \times 10^{-3}$ & response to nutrient & $3.9 \times 10^{-3}$ \\
\hline acute-phase response & $1.5 \times 10^{-3}$ & T cell differentiation in thymus & $4.4 \times 10^{-3}$ \\
\hline cellular response to nutrient levels & $1.7 \times 10^{-3}$ & retinol metabolic process & $4.8 \times 10^{-3}$ \\
\hline positive regulation of smooth muscle cell proliferation & $1.7 \times 10^{-3}$ & positive regulation of natural killer cell activation & $5.0 \times 10^{-3}$ \\
\hline regulation of membrane potential & $1.9 \times 10^{-3}$ & leukotriene biosynthetic process & $7.0 \times 10^{-3}$ \\
\hline response to peptide hormone & $1.9 \times 10^{-3}$ & positive regulation of T cell mediated cytotoxicity & $7.9 \times 10^{-3}$ \\
\hline cholesterol metabolic process & $1.9 \times 10^{-3}$ & secretion of lysosomal enzymes & $9.2 \times 10^{-3}$ \\
\hline ribosome biogenesis & $1.9 \times 10^{-3}$ & cellular response to calcium ion & $9.5 \times 10^{-3}$ \\
\hline fatty acid biosynthetic process & $2.2 \times 10^{-3}$ & response to oxidative stress & $9.7 \times 10^{-3}$ \\
\hline response to estrogen & $2.5 \times 10^{-3}$ & sphingolipid metabolic process & $1.0 \times 10^{-2}$ \\
\hline negative regulation of Notch signaling pathway & $2.6 \times 10^{-3}$ & & \\
\hline synapse assembly & $2.7 \times 10^{-3}$ & & \\
\hline cell adhesion & $2.9 \times 10^{-3}$ & & \\
\hline superoxide metabolic process & $3.0 \times 10^{-3}$ & & \\
\hline oxidation-reduction process & $3.2 \times 10^{-3}$ & & \\
\hline
\end{tabular}

Figure 2. RNA expression modifications in enriched Hdac1 and Hdac2 deleted jejunal intestinal epithelial cells. (A) Top canonical pathways for increased or decreased transcripts were identified by IPA analysis. (B) Gene ontology analysis of biological processes for increased or decreased transcripts was performed with the DAVID 2.0 EASE Score. $p$-value < 0.05; fold-change: more than 2-fold or less than 0.5-fold. 
A Top canonical pathways for increased or decreased TMT-labeled proteins identified by IPA analysis

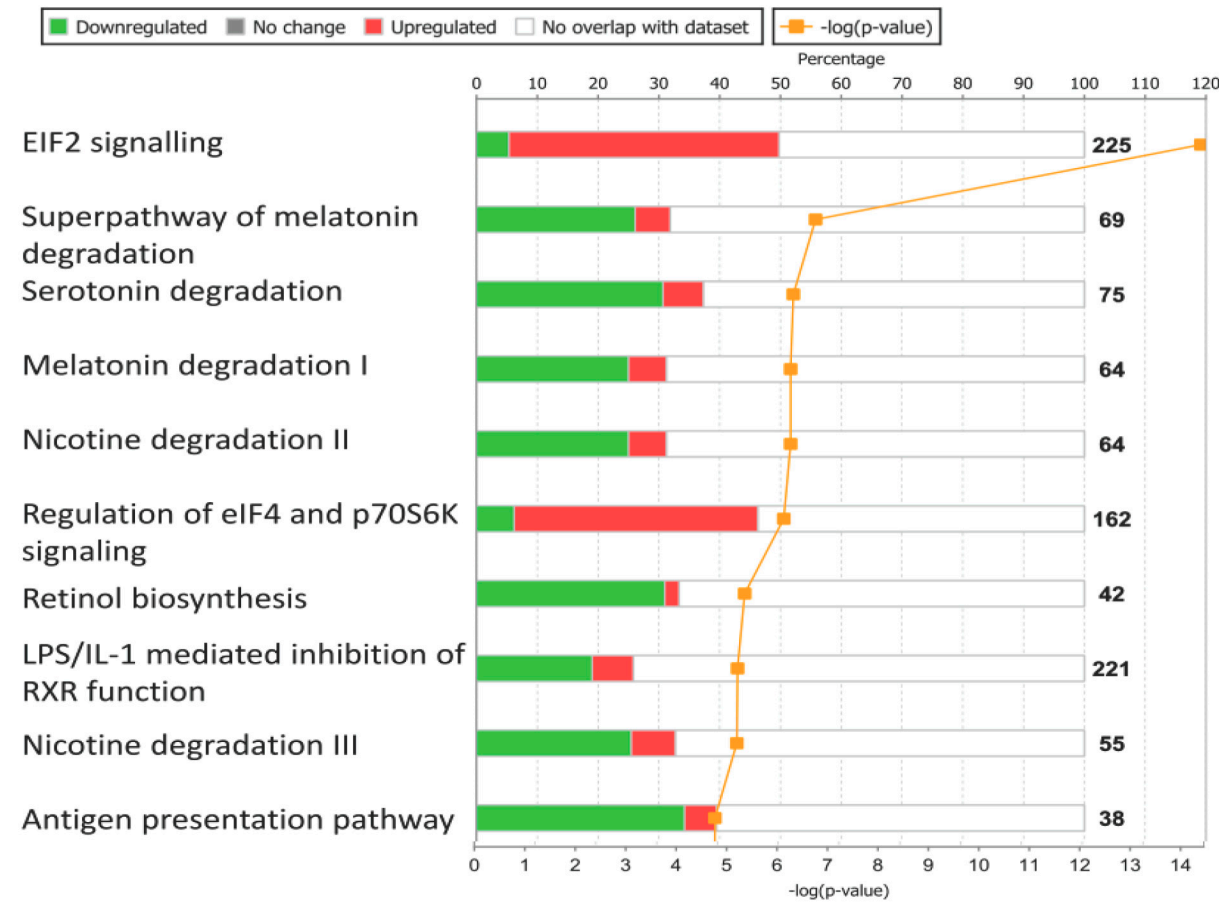

B Gene ontology analysis of biological processes for increased or decreased TMT-labeled proteins

\begin{tabular}{|c|c|c|c|}
\hline \multicolumn{4}{|c|}{ GOTERM_BP_DIRECT of IEC-HDAC1/2 deleted proteins } \\
\hline Proteins increased by $>1.5$ & P-value & Proteins decreased by $<0.75$ & P-value \\
\hline translation & $1,36 \times 10^{-30}$ & oxidation-reduction process & $2,80 \times 10^{-18}$ \\
\hline cytoplasmic translation & $1,28 \times 10^{-13}$ & nucleosome assembly & $2,30 \times 10^{-16}$ \\
\hline ribosomal small subunit assembly & $8,37 \times 10^{-10}$ & defense response & $3,50 \times 10^{-12}$ \\
\hline cell-cell adhesion & $1,63 \times 10^{-8}$ & chromatin silencing & $6,00 \times 10^{-9}$ \\
\hline maturation of LSU-rRNA from tricistronic & $3,22 \times 10^{-5}$ & defense response to bacterium & $2,10 \times 10^{-8}$ \\
\hline maturation of SSU-rRNA from tricistronic & $8,46 \times 10^{-5}$ & lipid metabolic process & $3,80 \times 10^{-8}$ \\
\hline metabolic process & $9,10 \times 10^{-5}$ & defense response to Gram-positive bacteria & $6,80 \times 10^{-8}$ \\
\hline rRNA processing & $2,43 \times 10^{-4}$ & fatty acid beta-oxidation & $2,60 \times 10^{-7}$ \\
\hline translational initiation & $2,53 \times 10^{-4}$ & metabolic process & $5,40 \times 10^{-7}$ \\
\hline protein folding & $2,73 \times 10^{-4}$ & antibacterial humoral response & $4,40 \times 10^{-6}$ \\
\hline glycolytic process & $2,92 \times 10^{-4}$ & steroid metabolic process & $9,90 \times 10^{-6}$ \\
\hline RNA secondary structure unwinding & $8,37 \times 10^{-4}$ & chromatin silencing at rDNA & $1,70 \times 10^{-5}$ \\
\hline translational elongation & $1,02 \times 10^{-3}$ & defense response to Gram-negative bacterium & $2,00 \times 10^{-5}$ \\
\hline glutathione metabolic process & $1,24 \times 10^{-3}$ & fatty acid metabolic process & $2,50 \times 10^{-5}$ \\
\hline ribosomal small subunit biogenesis & $3,53 \times 10^{-3}$ & antigen processing and presentation & $3,10 \times 10^{-5}$ \\
\hline endonucleolytic cleavage in ITS1 & $3,89 \times 10^{-3}$ & fatty acid beta-oxidation using acyl-CoA dehydrogenase & $3,60 \times 10^{-5}$ \\
\hline regulation of translation & $3,93 \times 10^{-3}$ & innate immune response in mucosa & $6,00 \times 10^{-5}$ \\
\hline gene silencing by RNA & $1,12 \times 10^{-2}$ & antigen processing and presentation & $8,80 \times 10^{-5}$ \\
\hline regulation of proteasomal ubiquitin & $1,35 \times 10^{-2}$ & response to drug & $1,00 \times 10^{-4}$ \\
\hline regulation of translational initiation & $1,68 \times 10^{-2}$ & aromatic compound catabolic process & $1,70 \times 10^{-4}$ \\
\hline Iysosome organization & $2,62 \times 10^{-2}$ & cellular aromatic compound metabolic process & $3,00 \times 10^{-4}$ \\
\hline maturation of SSU-rRNA & $2,79 \times 10^{-2}$ & DNA methylation on cytosine & $4,90 \times 10^{-4}$ \\
\hline phosphorus metabolic process & $3,27 \times 10^{-2}$ & DNA replication-dependent nucleosome assembly & $5,70 \times 10^{-4}$ \\
\hline endonucleolytic cleavage & $3,27 \times 10^{-2}$ & positive regulation of gene expression & $5,70 \times 10^{-4}$ \\
\hline protein homotetramerization & $3,39 \times 10^{-2}$ & antigen processing via MHC class I & $8,60 \times 10^{-4}$ \\
\hline cellular zinc ion homeostasis & $3,48 \times 10^{-2}$ & antigen processing and presentation & $8,90 \times 10^{-4}$ \\
\hline \multirow[t]{2}{*}{ osteoblast differentiation } & $3,92 \times 10^{-2}$ & peptide catabolic process & $1,00 \times 10^{-3}$ \\
\hline & & lipid homeostasis & $1,60 \times 10^{-3}$ \\
\hline
\end{tabular}

Figure 3. Protein expression modifications in enriched Hdac1 and Hdac2 deleted jejunal intestinal epithelial cells. (A) Top canonical pathways for increased or decreased TMT-labeled proteins were identified by IPA analysis. (B) Gene ontology analysis of biological processes for increased or decreased TMT-labeled proteins was performed with the DAVID 2.0 EASE Score. $p$-value $<0.05$; fold-change: more than 1.5 -fold and less than 0.75 -fold. 
Previous microarray and QPCR analysis with total mucosal RNA preparations from mutant colons indicated an inflammatory state in mutant mice, associated with differentiation defects. Here, we measured by qPCR intrinsic gene expression changes in enriched $H d a c$-deleted IEC, without the mucosal portions. C-type lectin $\operatorname{Reg} 3 \beta$ and $\operatorname{Reg} 3 \gamma$ gene expression was increased (Figure $4 \mathrm{~A}$ ). This antimicrobial peptide family controls intestinal barrier processes, in part by controlling luminal bacterial content and by regulating innate as well as adaptive mucosal immune responses [40]. Paneth cell differentiation was altered, as exemplified by decreased expression of antimicrobial Cryptdin (Figure 4A), and of novel markers including the Krüppel-like transcription factor Klf15 and the mucosal pentraxin Mptx2 (respectively - 2.781 and -2.26 ( $\left.\log _{2}\right)$ ) ([41]; Supplementary Table S3). Some enteroendocrine cell (EEC) hormone genes expressed in different EEC subsets were increased, such as ChgA encoding a neuroendocrine secretory protein (Figure 4A), and secretin $(S c t)$, a pan-EEC marker $\left(4.094\left(\log _{2}\right)\right)$, or decreased (Gastric inhibitory peptide (Gip), -1.255 $\left(\log _{2}\right)$; Glucagon $\left.(G c g)-1.266\left(\log _{2}\right)\right)$. Other subset-specific EEC genes, such as Neurotensin (Nts) and Somatostatin $(S s t)$, were decreased $\left(-1.31,-3.966\left(\log _{2}\right)\right.$, Supplementary Table S3) $[7,41]$. Enterocyte and goblet cell differentiation was altered (Figure 4B, $4 C)$. Indeed, enterocyte-expressed Slc15a1, encoding the brush border intestinal hydrogen peptide cotransporter PepT1 [42], Sis, encoding the brush border sucrase-isomaltase and Fabp2, encoding a fatty acid protein involved in long-chain fatty acid uptake and transport, were decreased, while Alpi, an alkaline phosphatase gene with anti-inflammatory properties, namely through bacterial lipopolysaccharide detoxification, was increased [43,44] (Figure 4B). Goblet-expressed Tff3, encoding a repair-inducing protective Trefoil family secretory protein [45], Muc2, encoding a secreted mucin involved in mucous barrier formation, and $\mathrm{Zg16}$, encoding a lectin-like protein acting as a bacterial segregator [46], were decreased (Figure 4C). Thus, while differentiation and function of the three main IEC types, namely enterocytes, secretory Paneth and goblet cells, are altered in knockout cells, a number of protective genes, including Reg and Alpi genes, are increased, and may play important roles to ensure tissue homeostasis.

We also observed decreased expression of Atoh1, encoding an IEC secretory lineage differentiation regulator, and $L g r 5$, encoding an R-spondin receptor involved in stem IEC maintenance, as well as increased expression of Jag2, encoding a Notch receptor activating ligand, and Ccnd1, encoding the cell cycle regulator Cyclin D1 (Figure 4D). Thus, gene expression results on isolated IEC confirm that IEC-specific Hdac1 and Hdac2 deletion alters Notch signaling and stem cell marker expression, as well as IEC proliferation [18].

As Omics analysis suggested defects in pathways related to antigen processing and presentation, we verified MHC class II gene expression (Figure 4E). Indeed, IEC act as antigen-presenting cells, in part by expressing MHC class II genes and regulators both in differentiated cells [47] and in stem cell subtypes [48]. Recent data suggest that IEC-specific MHC class II gene deletion leads to increased intestinal stem cell numbers, as well as IEC differentiation and $\mathrm{T}$ cell activation defects [48]. qPCR analysis showed reduced expression of a number of MHC Class II genes, as well as the MHC Class II Ciita transcriptional regulator and Cd74, a chaperone associated with MHC Class II [47]. Thus, HDAC may be important regulators of MHC class II IEC expression patterns which could affect both the mucosal immune responses and IEC barrier homeostasis. 
A

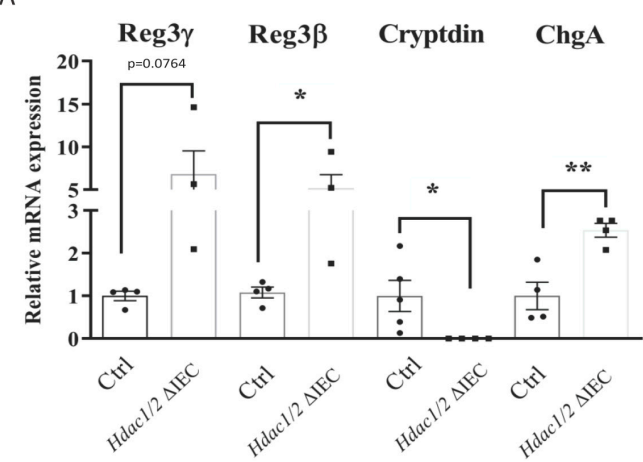

C

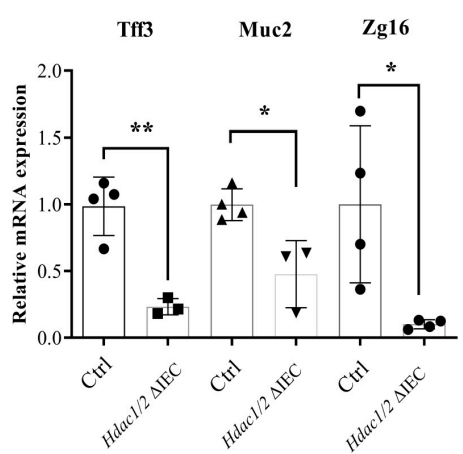

E

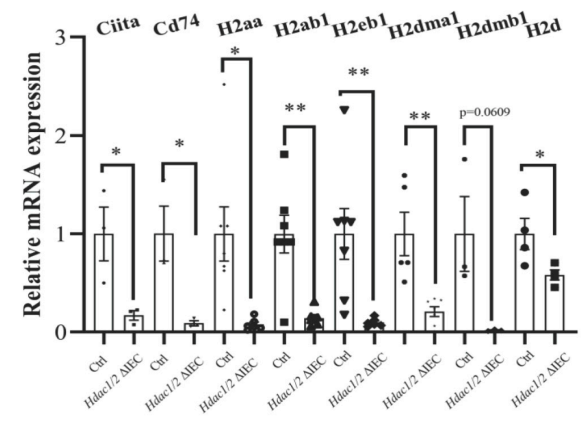

F

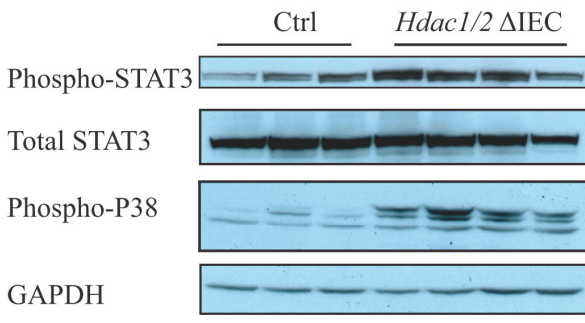

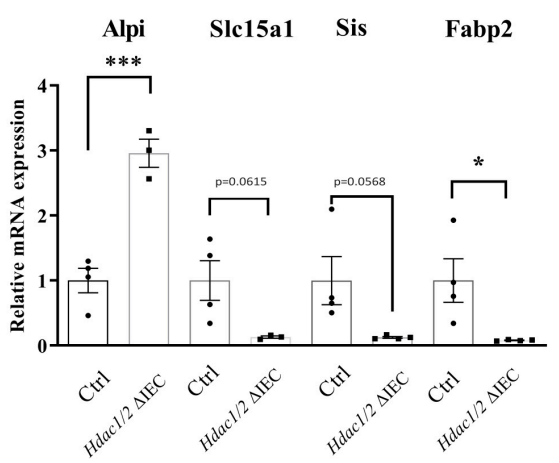

D

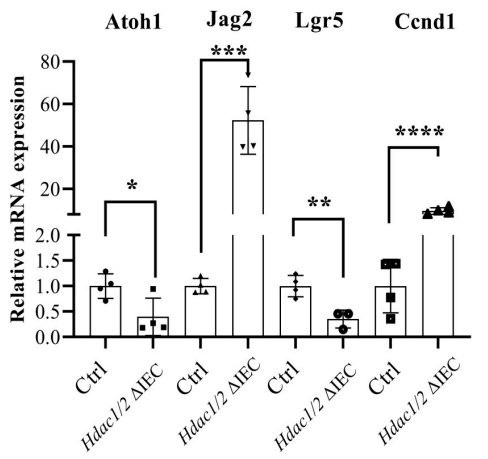

G

Claudin 3

GAPDH

Cleaved Notch

GAPDH

Phospho-S6

GAPDH
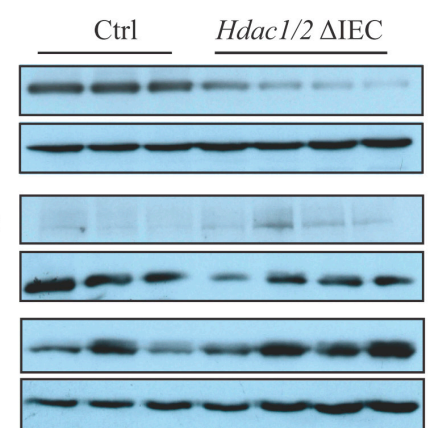

Figure 4. Hdac1 and Hdac2 deletion disrupts jejunal epithelial differentiation and MHC class II gene expression. Total RNA was purified from enriched control and $\mathrm{Hdac1}^{-/-} ; \mathrm{Hdac}^{-/-}$jejunal IEC. Expression levels of secretory cell differentiation marker Reg3g, Reg3b, Cryptdin and ChgA (A), enterocyte cell marker Alpi, Slc15a1, Sis and Fabp2 (B), goblet cell marker Tff3, Muc2 and Zg16 (C), differentiation, proliferation and stem cell marker Atoh1, Jag2, Lgr5, Ccnd1 (D), as well as MHC II genes Ciita, Cd74, H2aa, H2ab1, H2eb1, H2dma1, H2dmb1 and H2d (E) were measured by qPCR. Relative RNA amounts were determined by comparing to Pbgd amplification $(n=4-5)$. Results represent the mean $\pm \mathrm{SEM}\left({ }^{*} p \leq 0.05\right.$; $\left.{ }^{* *} p \leq 0.01 ;{ }^{* * *} p \leq 0.005 ;{ }^{* * *} p \leq 0.001\right)$. Protein extracts enriched from control and Hdac1 ${ }^{-/-} ; \mathrm{Hdac} 2^{-/-}$jejunal IEC were separated on $8 \%$ or $10 \%$ SDS-PAGE gels and transferred to PVDF membranes for Western blot analysis of phospho-STAT3, total STAT3 and phospho-p38 (F), or claudin 3, cleaved Notch and phospho-S6 (G). GAPDH was used as loading control for each membrane. 
We then assessed the intrinsic IEC effect of Hdac and Hdac2 deletion on signal transduction pathways, by Western blot analysis of IEC-enriched protein extracts. Both STAT3 and p38 inflammatory signaling was induced in Hdac-deleted IEC, as shown by increasing STAT3 and p38 phosphorylated forms as opposed to control IEC (Figure 4F). Notch signaling was increased, as assessed by augmented levels of cleaved Notch (Figure 4G). Notch signalling activation not only maintains intestinal epithelial stem cells, but also regulates IEC progenitor differentiation into enterocytes while repressing the secretory differentiation pathway [49]. In addition, the mTOR kinase pathway was activated, as shown by increased levels of phospho-ribosomal S6 protein, a downstream target of S6 kinases (Figure 4G). mTOR may play a role in intestinal regeneration upon injury [50]. Intrinsic IEC mTOR pathway activation is thus associated with increased small intestinal growth in IEC-specific Hdac1 and Hdac2 deleted mice [18]. Finally, protein levels of CLDN3, a component of tight junctions regulating IEC polarity and barrier functions, and a marker of intestinal barrier integrity [51], were reduced (Figure 4G).

Thus, IEC-specific Hdac1 and Hdac2 deletion leads to activation of Notch, Stat3 and mTOR pathways involved in stemness, differentiation and inflammatory responses. Results obtained in different cell lines have uncovered crosstalk interactions between these pathways. For example, mTOR may phosphorylate and activate Stat3 [52]. A mTORStat3-Notch pathway is involved in the control of murine embryonic fibroblast and human breast cancer cell line differentiation [53]. Notch receptor ligands may lead to Stat3 activation of Hes family members in neural stem cells [54]. Finally, Notch activation may induce mTOR activation during liver lipogenesis $[55,56]$. To determine the impact of these pathways on the mutant mouse phenotype, we focused on the Notch and Stat3 pathways. We treated mice respectively with Dibenzazepine (DBZ), a Notch $/ \gamma$-secretase inhibitor, to block the Notch pathway [57], and Tofacitinib, a JAK kinase inhibitor, to block the JAK-STAT pathway [58].

As observed before, IEC-specific Hdac1 and Hdac2 deletion resulted in decreased secretory Paneth and goblet cell numbers, crypt elongation and impaired epithelial polarity, as evidenced by disrupted nuclear staining and localization ([18]; Supplementary Figure S2A). In contrast to control mice, DBZ treatment was lethal to some mutant mice. DBZ treatment increased the number of goblet cells in control mice. $\mathrm{H}$ and $\mathrm{E}$ staining of jejunal sections from surviving mutant mice revealed an increase in the number of goblet cells and eosinophilic granule-stained Paneth cells in the crypt. Thus, by blocking the Notch pathway, IEC secretory lineage differentiation was increased in both control and mutant mice However, it was quite evident that DBZ treatment intensified epithelial disruption in mutant mice. As Notch signaling is involved in maintaining stem cell pools, we have injected mice with BrdU and evaluated proliferation in intestinal crypts (Supplementary Figure S2B). As observed before, IEC-specific Hdac1 and Hdac2 deletion led to enhanced crypt proliferation and expansion. In contrast to control mice, DBZ treatment decreased proliferative cell numbers at the bottom of the crypts, with some proliferative cells maintained in the upper crypt region. Thus, IEC-specific Hdac1 and Hdac2 deletion renders mice more sensitive to Notch signaling alterations. Diversion of stem cells towards secretory cell differentiation may deplete the stem cell pool, thereby affecting epithelial maintenance in an injury-like setting, such as found in the mutant Hdac1 and Hdac2 deletion mouse mucosa.

To determine the importance of Stat3, a major pathway activated in dual IEC-specific Hdac1 and Hdac2-deficient mice, we inhibited Stat signaling with Tofacitinib, a JAK inhibitor. As opposed to control mutant mice, Tofacitinib treatment led to partial restoration of nuclear basal epithelial localization, as assessed by $\mathrm{H}$ and $\mathrm{E}$ staining (Figure 5A). In control mice, immunofluorescence staining showed that CLDN3 was restricted to basolateral membranes in both jejunal upper crypt and villus compartments (Figure 5B), as observed in rat duodenal stained sections [59]. In mutant mucosa, in addition to decreased CLDN3 expression, CLDN3 was delocalized (Figure 5B). In contrast, Tofacitinib treatment restored both CLDN3 levels and basolateral localization, suggesting amelioration of barrier 
function. Finally, we assessed crypt cell proliferation after BrdU staining. While crypt cell proliferative numbers were enhanced in mutant mice, Tofacitinib treatment reduced the number of BrdU positive cells to intermediary levels, in comparison to control mice. (Figure 5C,D). This correlated with the appearance of Paneth cells that help to stabilize the crypt niche in mutant mice. While Tofacitinib treatment did not increase goblet cell numbers in mutant mice, as assessed by Alcian blue staining, Paneth cell numbers were increased, as shown by increased Lysozyme- and Best's Carmine-stained cells in the crypt, as well as by increased numbers of crypts containing more than one Paneth cell, as opposed to non-treated mutants (Figure 6A-C).

We had found previously increased immune $\mathrm{T}$ cell recruitment in the colon of villinCre dual Hdac1 ${ }^{-/-} ; \mathrm{Hdac}^{-/-}$mice [25]. As opposed to wild-type mice, we did observe more abundant immune $\mathrm{T}$ cells in mutant murine jejunal villi and bottom crypt regions, as assessed by $\mathrm{CD} 3$ antibody staining (Figure 7A). Increased CD3+ immune cell numbers correlate with intestinal inflammation observed in mutant mice. This could be a response to barrier defect and antimicrobial secreting Paneth cell loss. Treatment with Tofacitinib reduced the number of recruited $\mathrm{T}$ cells, notably in the surrounding crypt region, as observed with the decreased number of CD3+ cells around the crypt in treated mutant mice (Figure 7B).

We then determined the status of STAT3 activation in mutant mice treated without or with Tofacitinib, by analysing STAT3 nuclear localization by immunohistochemistry. In control mice, STAT3 was localized in the cytoplasm of IEC in the villi as well as in the top portion of the crypts (Figure 7C). Mutant jejunal epithelium displayed increased STAT3 nuclear staining along the crypt-villus axis. STAT3 labeled lamina propria cells were increased in the crypt region and the bottom of the villi (Figure 7C). Tofacitinib treatment reduced STAT3 nuclear staining, more prominently in the bottom of the villi. (Figure 7C). Thus, Tofacitinib treatment partially restored STAT3 nuclear levels to wild-type levels, in mutant mice.

We then verified the status of mTOR pathway activation by staining with an antibody against phospho-S6 protein, a marker of mTOR activation. In control mice, we observed phospho-S6 staining restricted to two defined regions, namely in the top crypt and bottom villus region, and in the villus tip region (Figure 7D). This staining is associated with regionspecific enterocyte functions. Indeed, while bottom villus region-located enterocytes are associated with biosynthetic efficiency and an antimicrobial pattern of expression, including Reg genes, enterocytes at the villus tips express cell adhesion and purine catabolism genes and are associated with an anti-inflammatory program [4]. Mutant mice displayed increased phospho-S6 staining which expanded in the middle villus regions (Figure 7D). While some phospho-S6 stained patches were maintained in middle villus sections, Tofacitinib treatment reduced overall phospho-S6 staining expansion in mutant mice. Moreover, it has been observed that mTOR inactivation in intestinal epithelial cells blocks Notch signalling, which in turn increases Paneth cell numbers [60]. In mutant mice, Paneth cell number increases after Tofacitinib treatment may indirectly stem from both mTOR and Notch inhibition.

Thus, JAK/STAT inhibition in mutant mice leads to partial restoration of the epithelium, notably in the crypt, concomitant with Notch signaling inhibition, as exemplified by increased production of Paneth cells. Barrier and cell polarity are improved, as shown by restoration of baso-lateral CLDN3 expression and apico-basal organization, and with mTOR signaling recovery. In addition, mTOR signaling is partly recovered, as evidenced by recovery of phospho-S6 expression pattern in the epithelial mucosa. Our data show that JAK/STAT pathway is an important regulator of Notch and mTOR pathway activation in response to HDAC1 and HDAC2-dependent epigenetic IEC alterations. Tofacitinib-mediated inhibition of JAK-STAT signaling in IEC could well synergize with its anti-inflammatory role in immune cells [61], thereby impacting mucosal recovery during inflammation. 
A

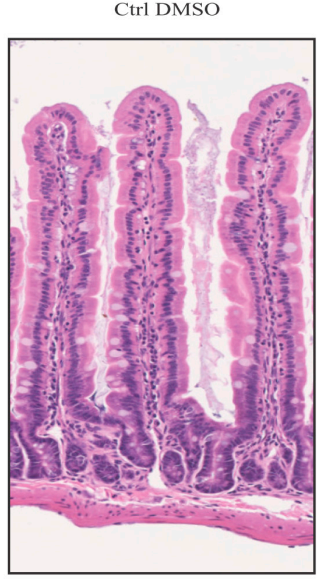

B

HE staining

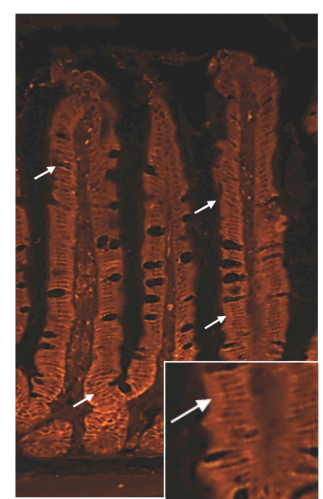

c

Ctrl DMSO

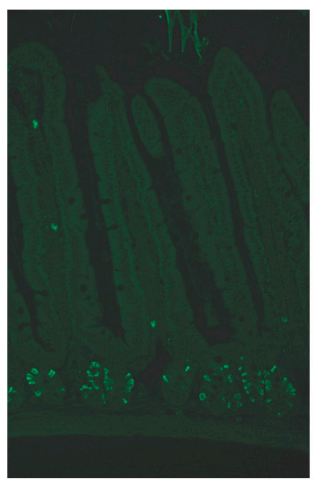

D

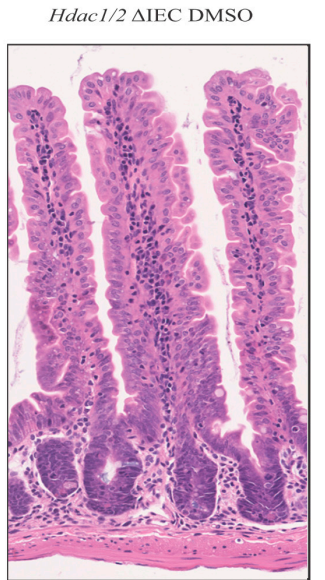

Hdac1/2 $\triangle \mathrm{IEC}$ DMSO

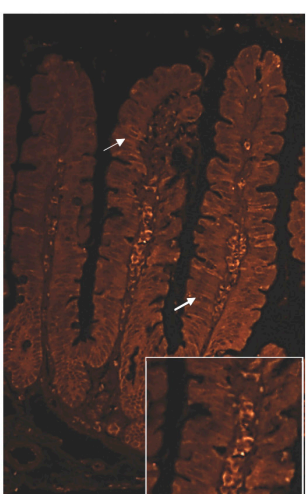

Hdac 1/2 $\triangle$ IEC DMSO

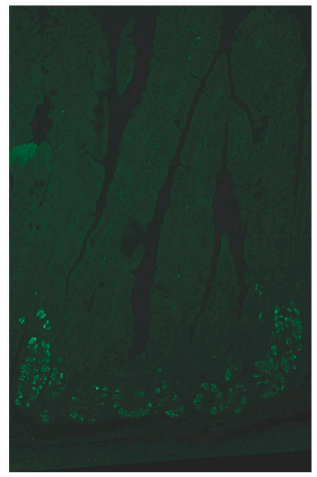

Hdacl/2 $\triangle \mathrm{IEC}$ TOFA

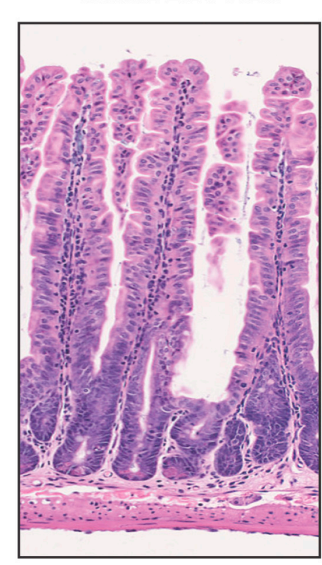

Hdacl/2 $\triangle \mathrm{IEC}$ TOFA

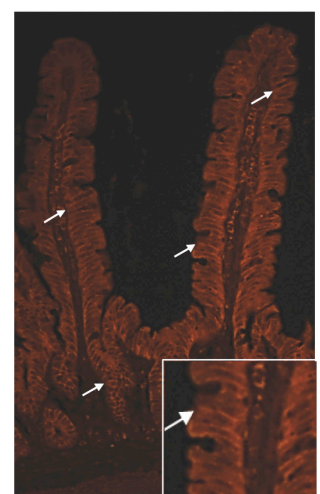

Hdac I/2 $\triangle$ IEC TOFA

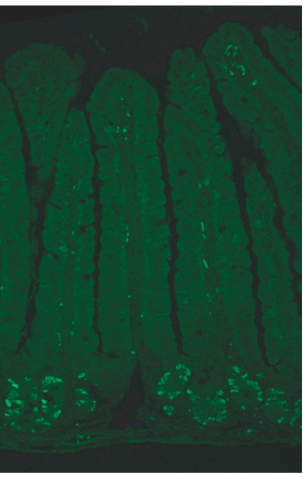

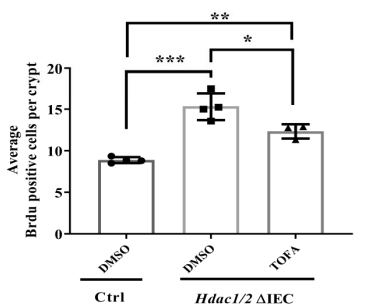

Figure 5. Tofacitinib treatment ameliorates intestinal architecture and decreases intestinal epithelial cell proliferation in villin-Cre Hdac1 and Hdac2 deficient mice. Jejunal tissue sections, from wild-type (Ctrl) and villin-Cre Hdac1 ${ }^{-/{ }^{-}}$; Hdac2 ${ }^{-/-}$ mice (Hdac1/2 $\triangle \mathrm{IEC}$ ) treated without or with Tofacitinib (DMSO or TOFA) for five days, were stained with hematoxylin and eosin (HE) (A) (Magnification: $10 \times$ ) or were stained with an antibody against claudin $3(n=3)$ (white arrows) (B) (Magnification: $20 \times$ ). (C) Wild-type (Ctrl) and villin-Cre Hdac1 ${ }^{-/-}$; Hdac2 ${ }^{-/-}$mice, treated without or with Tofacitinib (DMSO or TOFA) for five days, were injected with BrdU for $2 \mathrm{~h}$. Jejunal tissue sections were stained with an antibody against incorporated BrdU. Magnification: $10 \times$. (D) The average number of BrdU-labeled proliferative cells per jejunal crypts was measured $\left(n=3,20-30\right.$ crypts each). Results represent the mean $\pm \operatorname{SEM}\left({ }^{*} p \leq 0.05 ;{ }^{* *} p \leq 0.01 ;{ }^{* * *} p \leq 0.005\right)$. 
A

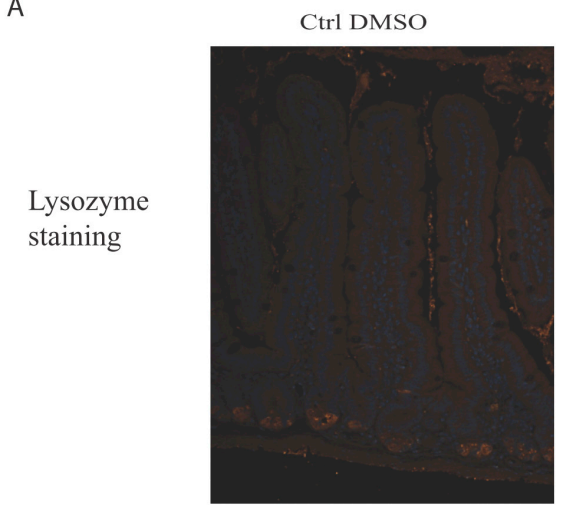

B Alcian Blue and Best's Carmine staining

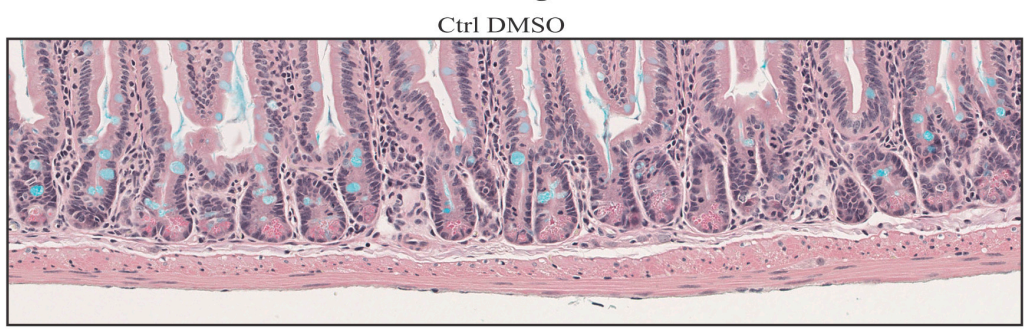

Hdac l/2 $\triangle$ IEC DMSO

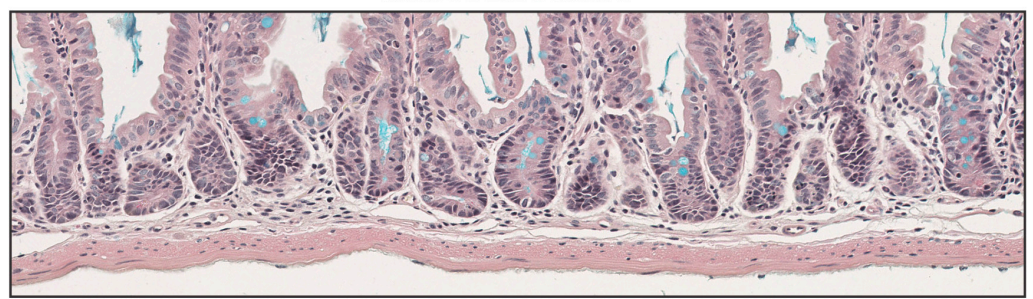

Hdac 1/2 $\triangle$ IEC TOFA

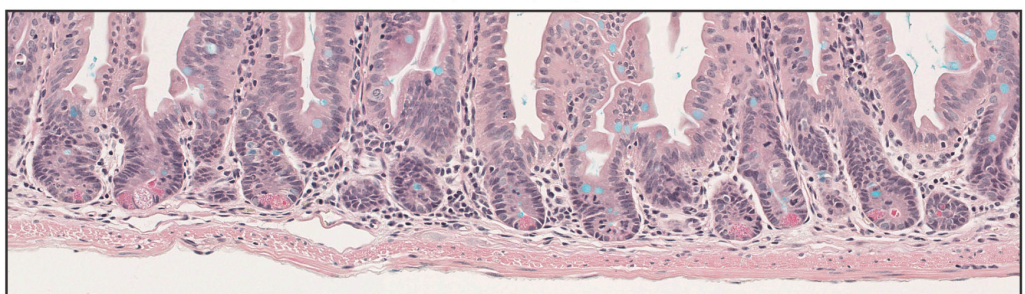

C

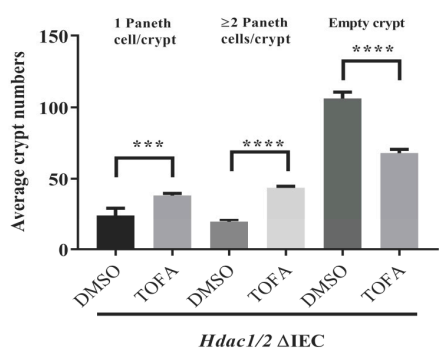

Figure 6. Tofacitinib treatment increases the number of Paneth cells in villin-Cre Hdac1 and Hdac2 deficient mice. Jejunal tissue sections, obtained from wild-type (Ctrl) as well as villin-Cre $H d a c 1^{-/-} ; H d a c 2^{-/-}$mice $(H d a c 1 / 2 \Delta$ IEC) treated without or with Tofacitinib (DMSO or TOFA) for five days, were stained with an antibody against lysozyme for Paneth cell staining (white arrows), and merged with DAPI nuclear staining (A), or with Best's Carmine for Paneth cell staining (black arrows) and Alcian Blue for goblet cell staining (B). Magnification 10×. (C) The average number of crypts with none, or with one, two or more Paneth cells was compared between jejunal tissue sections from villin-Cre $\mathrm{Hdac1} 1^{-/-} ; \mathrm{Hdac}^{-/-}$ mice treated without or with Tofacitinib (DMSO or TOFA) $(n=3,150$ crypts each). Results represent the mean \pm SEM $\left({ }^{* * *} p \leq 0.005 ; * * * * 0.001\right)$. 
A

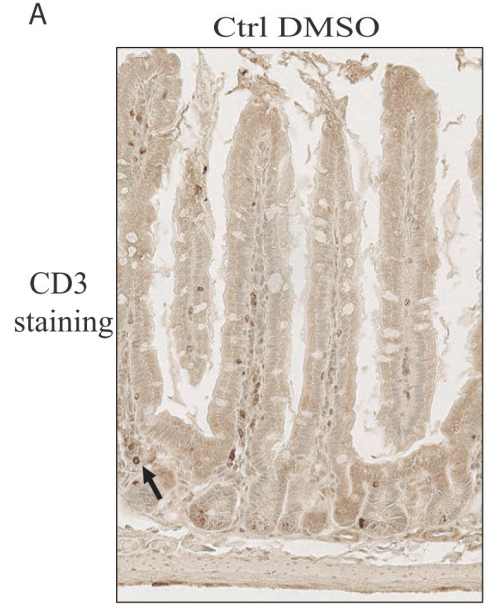

C

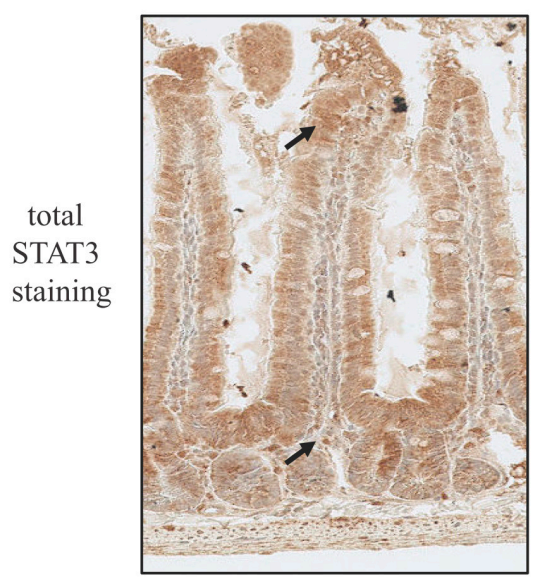

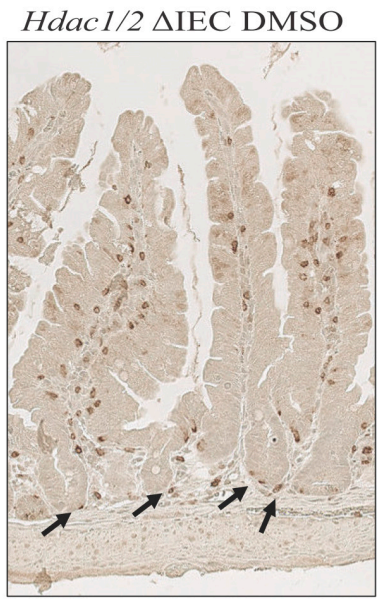

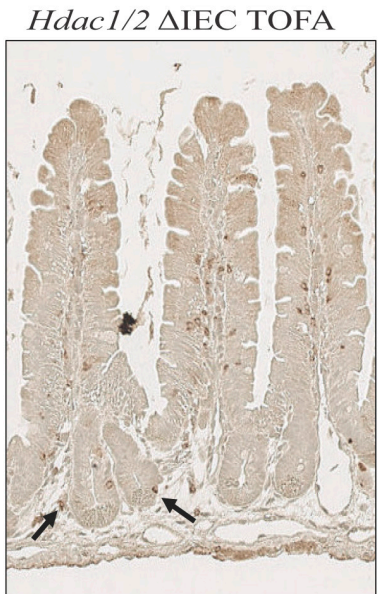

B
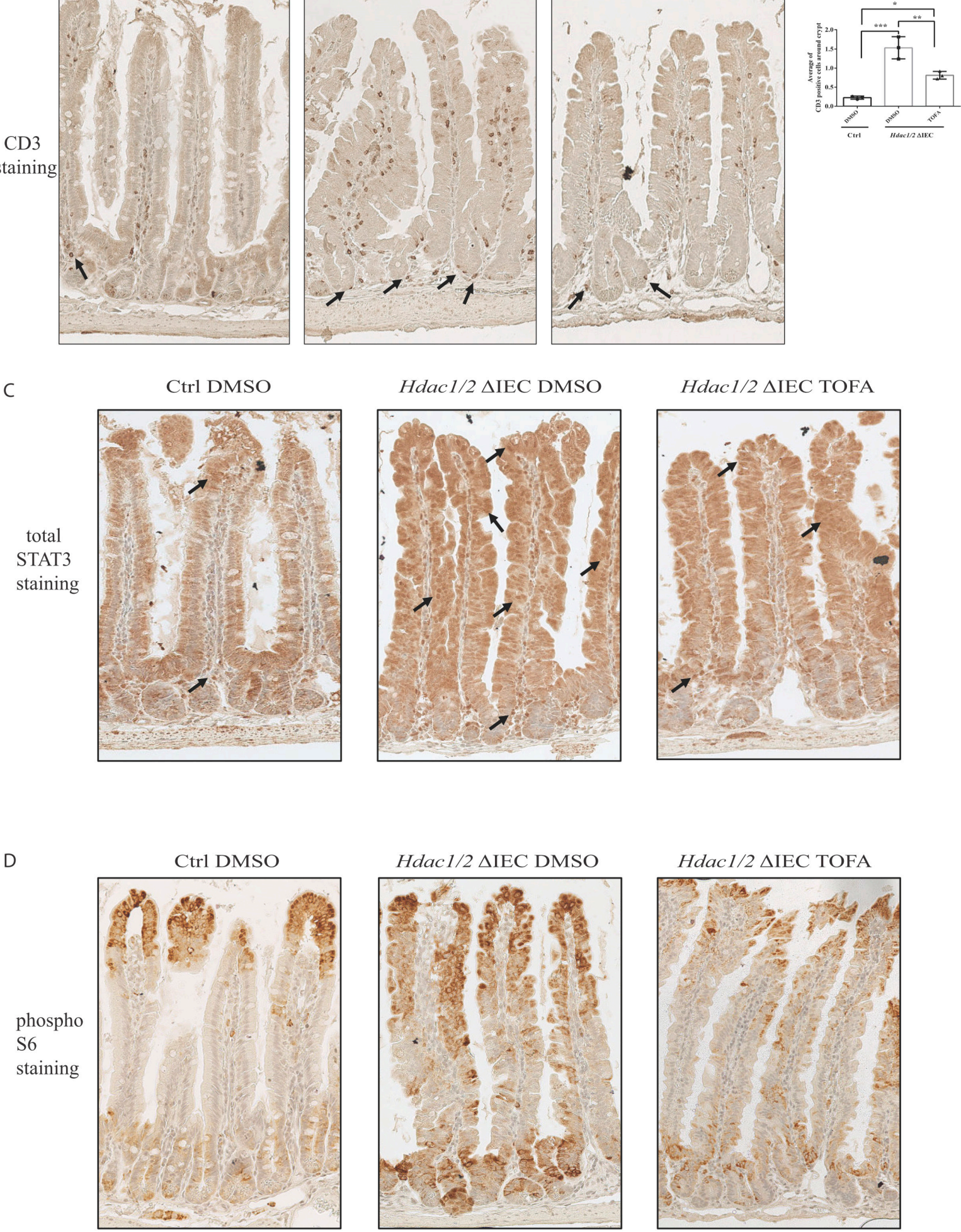

Hdac1/2 $\triangle$ IEC TOFA
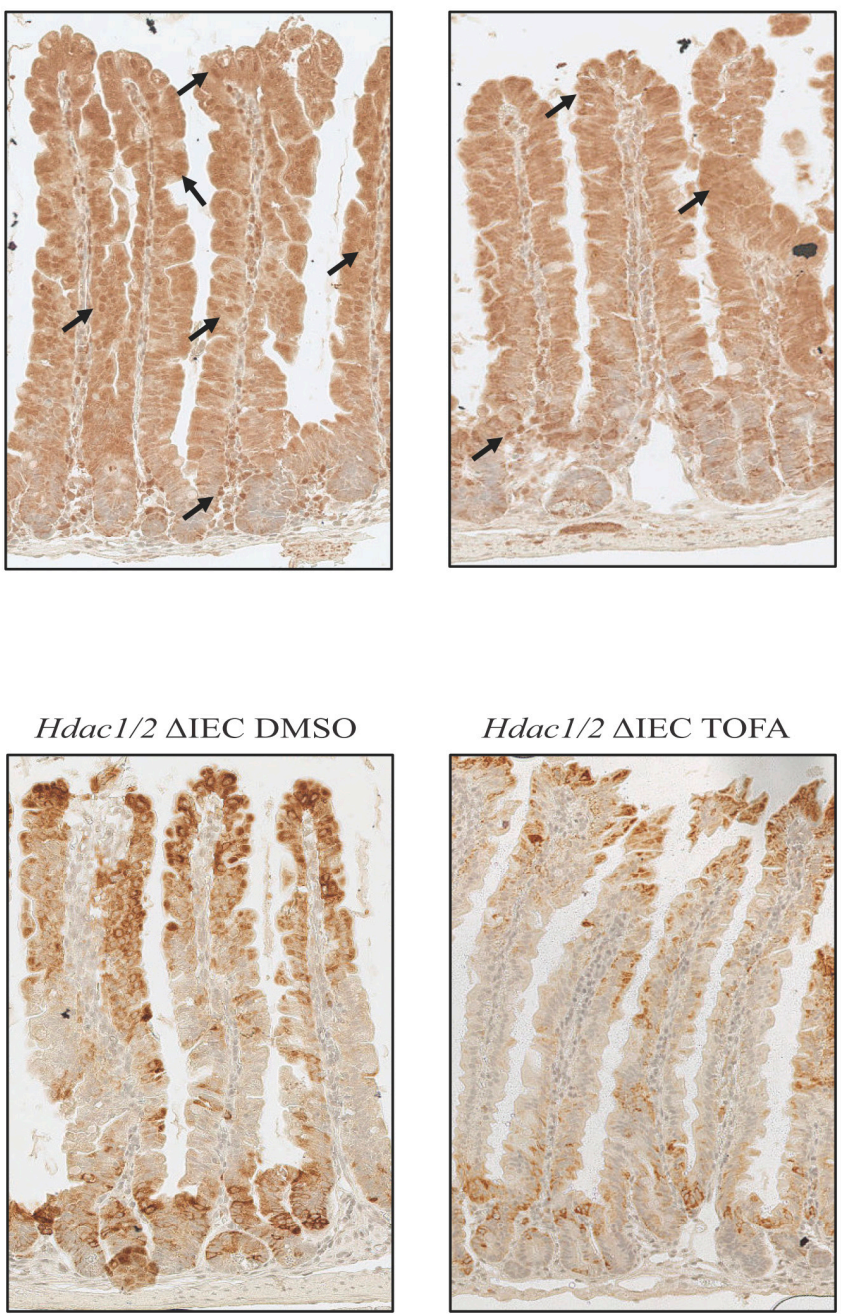

Hdac1/2 $\triangle$ IEC TOFA

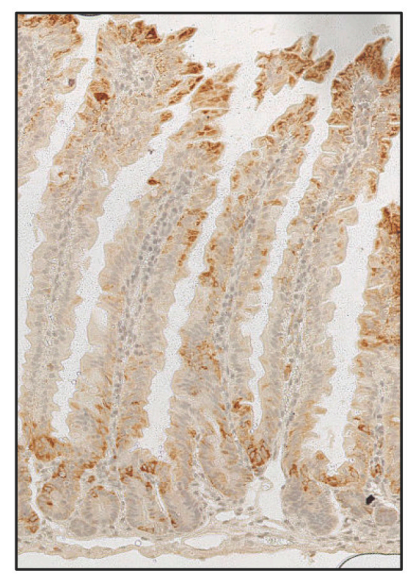

Figure 7. Tofacitinib treatment reduces $\mathrm{T}$ cell numbers and partially restores mTOR and JAK/STAT signaling pathways in villin-Cre Hdac1 and Hdac2 deficient mice. Jejunal tissue sections, from wild-type (Ctrl) as well as villin-Cre $H_{d a c}{ }^{-/-}$; $H$ dac $2^{-/-}$mice (Hdac1/2 $\triangle \mathrm{IEC}$ ) treated without or with Tofacitinib (DMSO or TOFA) for five days, were stained with an antibody against CD3 for T cells. T cells are marked by black arrows (A). Average number of CD3+ cells around crypts is shown in (B) Results represent the mean $\pm \operatorname{SEM}\left({ }^{*} p \leq 0.05 ;{ }^{* *} p \leq 0.01 ;{ }^{* *} p \leq 0.005\right)$. Jejunal tissue sections were stained with an antibody against STAT3 (C) and against phospho-S6 ribosomal protein (D). Magnification: 10×. 
Supplementary Materials: The following are available online at https: / /www.mdpi.com/2073-4 409/10/2/224/s1. Figure S1: Enteroid growth is disrupted after Hdac1 and Hdac2 deletion. Representative micrographs of $\mathrm{Hdac}^{-/-} ; \mathrm{Hdac}^{-/-}$villin-Cre enteroids grown for 24 or $72 \mathrm{~h}(n=3)$. Magnification: $5 \times$. Figure S2: Villin-Cre Hdac1 and Hdac2 deficient mice are more sensitive to Notch pathway inhibition by DBZ. A. Jejunal tissue sections, from wild-type (Ctrl) as well as villin-Cre $H d a c 1^{-/-} ; H d a c 2^{-/-}$mice (Hdac1/2 $\triangle \mathrm{IEC}$ ) treated without or with DBZ (DMSO or DBZ) for five days, were stained with hematoxylin and eosin $(\mathbf{A})$ (Magnification: $10 \times)$. B. Wild-type (Ctrl), as well as villin-Cre Hdac1 $1^{-/-}$; Hdac2 ${ }^{-/-}$mice treated without or with DBZ (DMSO or DBZ) for five days, were injected with BrdU for $2 \mathrm{~h}$. Jejunal tissue sections were stained with an antibody against incorporated BrdU. Magnification: $10 \times$. Table S1: List of upstream and downstream primers used for qPCR analysis. Table S2: List of antibodies used for immunofluorescence and Western blot analysis. Table S3: List of enriched Hdac1 and Hdac2 deleted jejunal intestinal epithelial cell mRNAs increased or decreased two-fold (fold-change: more than 2-fold and less than 0.5-fold). Table S4: List of enriched $H d a c 1$ and $H d a c 2$ deleted jejunal intestinal epithelial cell proteins increased or decreased by $50 \%$ (fold-change: more than 1.5-fold) and less than 0.75-fold). Table S5: List of enriched Hdac1 and Hdac2 deleted jejunal intestinal epithelial cell Disease and Bio functions (z-score) shared between RNA-seq and proteomics data. Table S6: List of enriched Hdac1 and Hdac2 deleted jejunal intestinal epithelial cell upstream regulators identified by IPA analysis from RNA-seq data and from proteomics data.

Author Contributions: A.G. performed all the experiments. N.T. was involved in the qPCR experiments. C.A. and A.G. wrote the manuscript. All authors contributed to data analysis. All authors reviewed the manuscript. F.B. and F.-M.B. are both implicated in data analysis and manuscript reviewing. All authors have read and agreed to the published version of the manuscript.

Funding: This work was supported by a grant from Crohn and Colitis Canada to Claude Asselin. Claude Asselin, François Boudreau and François-Michel Boisvert are members of the Fonds de recherche du Québec-Santé-funded CR-CHUS.

Institutional Review Board Statement: The study was conducted according to the guidelines of the Declaration of Helsinki, and approved by the or Ethics Committee CFPA-FMSS -Université de Sherbrooke, Sherbrooke, QC, CANADA (protocol 360-14B approved in March 2014).

Informed Consent Statement: Not applicable.

Data Availability Statement: The data supporting reported results can be found at: proteomeXchange Consortium through the PRIDE partner repository with the dataset identifier PXD (PXD022558) for proteomic data. RNA-Seq data have been deposited in the Gene Expression Omnibus database (GSE158522).

Acknowledgments: We thank E.N. Olson for providing Hdac1 and Hdac2 conditional knockout mice and S. Robine for villin-Cre ${ }^{E R}$ transgenic mice. We thank C. Kuo and G.R. van den Brink for providing the R-spondin 1- and Noggin-producing cell lines. We thank the Electron Microscopy and Histology research core for histology services, as well as the Proteomics research core, for proteome analysis.

Conflicts of Interest: The authors declare no conflict of interest.

\section{References}

1. Asselin, C.; Gendron, F.P. Shuttling of information between the mucosal and luminal environment drives intestinal homeostasis. FEBS Lett. 2014, 588, 4148-4157. [CrossRef] [PubMed]

2. Allaire, J.M.; Crowley, S.M.; Law, H.T.; Chang, S.Y.; Ko, H.J.; Vallance, B.A. The Intestinal Epithelium: Central Coordinator of Mucosal Immunity: (Trends in Immunology 39, 677-696, 2018). Trends Immunol. 2019, 40, 174. [CrossRef] [PubMed]

3. Gehart, H.; Clevers, H. Tales from the crypt: New insights into intestinal stem cells. Nat. Rev. Gastroenterol. Hepatol. 2019, 16, 19-34. [CrossRef] [PubMed]

4. Moor, A.E.; Harnik, Y.; Ben-Moshe, S.; Massasa, E.E.; Rozenberg, M.; Eilam, R.; Bahar Halpern, K.; Itzkovitz, S. Spatial Reconstruction of Single Enterocytes Uncovers Broad Zonation along the Intestinal Villus Axis. Cell 2018, 175, 1156-1167.e15. [CrossRef]

5. Knoop, K.A.; Newberry, R.D. Goblet cells: Multifaceted players in immunity at mucosal surfaces. Mucosal Immunol. 2018, 11, 1551-1557. [CrossRef]

6. Gassler, N. Paneth cells in intestinal physiology and pathophysiology. World J. Gastrointest. Pathophysiol. 2017, 8, 150-160. [CrossRef] 
7. Beumer, J.; Artegiani, B.; Post, Y.; Reimann, F.; Gribble, F.; Nguyen, T.N.; Zeng, H.; Van den Born, M.; Van Es, J.H.; Clevers, H. Enteroendocrine cells switch hormone expression along the crypt-to-villus BMP signalling gradient. Nat. Cell Biol. 2018, 20, 909-916. [CrossRef]

8. Beumer, J.; Gehart, H.; Clevers, H. Enteroendocrine Dynamics-New Tools Reveal Hormonal Plasticity in the Gut. Endocrine Rev. 2020, 41. [CrossRef]

9. Graham, D.B.; Xavier, R.J. Pathway paradigms revealed from the genetics of inflammatory bowel disease. Nature 2020, 578, 527-539. [CrossRef]

10. Ray, G.; Longworth, M.S. Epigenetics, DNA Organization, and Inflammatory Bowel Disease. Inflamm. Bowel Dis. 2019, 25, 235-247. [CrossRef]

11. Mokry, M.; Middendorp, S.; Wiegerinck, C.L.; Witte, M.; Teunissen, H.; Meddens, C.A.; Cuppen, E.; Clevers, H.; Nieuwenhuis, E.E. Many inflammatory bowel disease risk loci include regions that regulate gene expression in immune cells and the intestinal epithelium. Gastroenterology 2014, 146, 1040-1047. [CrossRef] [PubMed]

12. Kelly, D.; Kotliar, M.; Woo, V.; Jagannathan, S.; Whitt, J.; Moncivaiz, J.; Aronow, B.J.; Dubinsky, M.C.; Hyams, J.S.; Markowitz, J.F.; et al. Microbiota-sensitive epigenetic signature predicts inflammation in Crohn's disease. JCI Insight 2018, 3. [CrossRef] [PubMed]

13. Pietrocola, F.; Galluzzi, L.; Bravo-San Pedro, J.M.; Madeo, F.; Kroemer, G. Acetyl coenzyme A: A central metabolite and second messenger. Cell Metab. 2015, 21, 805-821. [CrossRef] [PubMed]

14. Newman, J.C.; Verdin, E. Ketone bodies as signaling metabolites. Trends Endocrinol. Metab. 2014, 25, 42-52. [CrossRef] [PubMed]

15. Liu, H.; Wang, J.; He, T.; Becker, S.; Zhang, G.; Li, D.; Ma, X. Butyrate: A Double-Edged Sword for Health? Adv. Nutr. 2018, 9, 21-29. [CrossRef]

16. Kelly, R.D.; Cowley, S.M. The physiological roles of histone deacetylase (HDAC) 1 and 2: Complex co-stars with multiple leading parts. Biochem. Soc. Trans. 2013, 41, 741-749. [CrossRef]

17. Moser, M.A.; Hagelkruys, A.; Seiser, C. Transcription and beyond: The role of mammalian class I lysine deacetylases. Chromosoma 2014, 123, 67-78. [CrossRef]

18. Turgeon, N.; Blais, M.; Gagne, J.M.; Tardif, V.; Boudreau, F.; Perreault, N.; Asselin, C. HDAC1 and HDAC2 restrain the intestinal inflammatory response by regulating intestinal epithelial cell differentiation. PLoS ONE 2013, 8, e73785. [CrossRef]

19. Leppkes, M.; Neurath, M.F.; Herrmann, M.; Becker, C. Immune deficiency vs. immune excess in inflammatory bowel diseasesSTAT3 as a rheo-STAT of intestinal homeostasis. J. Leukoc. Biol. 2016, 99, 57-66. [CrossRef]

20. Fritsch, S.D.; Weichhart, T. Metabolic and immunologic control of intestinal cell function by mTOR. Int. Immunol. 2020, 32, 455-465. [CrossRef]

21. Montgomery, R.L.; Davis, C.A.; Potthoff, M.J.; Haberland, M.; Fielitz, J.; Qi, X.; Hill, J.A.; Richardson, J.A.; Olson, E.N. Histone deacetylases 1 and 2 redundantly regulate cardiac morphogenesis, growth, and contractility. Genes Dev. 2007, 21, 1790-1802. [CrossRef] [PubMed]

22. Madison, B.B.; Dunbar, L.; Qiao, X.T.; Braunstein, K.; Braunstein, E.; Gumucio, D.L. Cis elements of the villin gene control expression in restricted domains of the vertical (crypt) and horizontal (duodenum, cecum) axes of the intestine. J. Biol. Chem. 2002, 277, 33275-33283. [CrossRef] [PubMed]

23. el Marjou, F.; Janssen, K.P.; Chang, B.H.; Li, M.; Hindie, V.; Chan, L.; Louvard, D.; Chambon, P.; Metzger, D.; Robine, S. Tissue-specific and inducible Cre-mediated recombination in the gut epithelium. Genesis 2004, 39, 186-193. [CrossRef] [PubMed]

24. Turgeon, N.; Gagne, J.M.; Blais, M.; Gendron, F.P.; Boudreau, F.; Asselin, C. The acetylome regulators Hdac1 and Hdac2 differently modulate intestinal epithelial cell dependent homeostatic responses in experimental colitis. Am. J. Physiol. Gastrointest. Liver Physiol. 2014, 306, G594-G605. [CrossRef] [PubMed]

25. Gonneaud, A.; Turgeon, N.; Boudreau, F.; Perreault, N.; Rivard, N.; Asselin, C. Distinct Roles for Intestinal Epithelial Cell-Specific Hdac1 and Hdac2 in the Regulation of Murine Intestinal Homeostasis. J. Cell. Physiol. 2016, 231, 436-448. [CrossRef]

26. Roskoski, R., Jr. Janus kinase (JAK) inhibitors in the treatment of inflammatory and neoplastic diseases. Pharmacol. Res. 2016, 111, 784-803. [CrossRef]

27. Sato, T.; Vries, R.G.; Snippert, H.J.; van de Wetering, M.; Barker, N.; Stange, D.E.; van Es, J.H.; Abo, A.; Kujala, P.; Peters, P.J.; et al. Single Lgr5 stem cells build crypt-villus structures in vitro without a mesenchymal niche. Nature 2009, 459, 262-265. [CrossRef]

28. Sato, T.; Clevers, H. Growing self-organizing mini-guts from a single intestinal stem cell: Mechanism and applications. Science 2013, 340, 1190-1194. [CrossRef]

29. Gonneaud, A.; Jones, C.; Turgeon, N.; Levesque, D.; Asselin, C.; Boudreau, F.; Boisvert, F.M. A SILAC-Based Method for Quantitative Proteomic Analysis of Intestinal Organoids. Sci. Rep. 2016, 6, 38195. [CrossRef]

30. Gonneaud, A.; Turgeon, N.; Jones, C.; Couture, C.; Levesque, D.; Boisvert, F.M.; Boudreau, F.; Asselin, C. HDAC1 and HDAC2 independently regulate common and specific intrinsic responses in murine enteroids. Sci. Rep. 2019, 9, 5363. [CrossRef]

31. Anders, S.; Huber, W. Differential expression analysis for sequence count data. Genome Biol. 2010, 11, R106. [CrossRef] [PubMed]

32. Cox, J.; Mann, M. MaxQuant enables high peptide identification rates, individualized p.p.b.-range mass accuracies and proteomewide protein quantification. Nat. Biotechnol. 2008, 26, 1367-1372. [CrossRef] [PubMed]

33. Dennis, G., Jr.; Sherman, B.T.; Hosack, D.A.; Yang, J.; Gao, W.; Lane, H.C.; Lempicki, R.A. DAVID: Database for Annotation, Visualization, and Integrated Discovery. Genome Biol. 2003, 4, P3. [CrossRef] [PubMed]

34. Kramer, A.; Green, J.; Pollard, J., Jr.; Tugendreich, S. Causal analysis approaches in Ingenuity Pathway Analysis. Bioinformatics 2014, 30, 523-530. [CrossRef] [PubMed] 
35. Carpenter, A.E.; Jones, T.R.; Lamprecht, M.R.; Clarke, C.; Kang, I.H.; Friman, O.; Guertin, D.A.; Chang, J.H.; Lindquist, R.A.; Moffat, J.; et al. CellProfiler: Image analysis software for identifying and quantifying cell phenotypes. Genome Biol. 2006, 7, R100. [CrossRef]

36. Roos, W.P.; Krumm, A. The multifaceted influence of histone deacetylases on DNA damage signalling and DNA repair. Nucleic Acids Res. 2016, 44, 10017-10030. [CrossRef]

37. Zimberlin, C.D.; Lancini, C.; Sno, R.; Rosekrans, S.L.; McLean, C.M.; Vlaming, H.; van den Brink, G.R.; Bots, M.; Medema, J.P.; Dannenberg, J.H. HDAC1 and HDAC2 collectively regulate intestinal stem cell homeostasis. FASEB J. Off. Publ. Fed. Am. Soc. Exp. Biol. 2015, 29, 2070-2080. [CrossRef]

38. Zhang, Y.; Edwards, P.A. FXR signaling in metabolic disease. Febs Lett. 2008, 582, 10-18. [CrossRef]

39. Sun, Y.; Iyer, M.; McEachin, R.; Zhao, M.; Wu, Y.M.; Cao, X.; Oravecz-Wilson, K.; Zajac, C.; Mathewson, N.; Wu, S.J.; et al. Genome-Wide STAT3 Binding Analysis after Histone Deacetylase Inhibition Reveals Novel Target Genes in Dendritic Cells. J. Innate Immun. 2017, 9, 126-144. [CrossRef]

40. Shin, J.H.; Seeley, R.J. Reg3 Proteins as Gut Hormones? Endocrinology 2019, 160, 1506-1514. [CrossRef]

41. Haber, A.L.; Biton, M.; Rogel, N.; Herbst, R.H.; Shekhar, K.; Smillie, C.; Burgin, G.; Delorey, T.M.; Howitt, M.R.; Katz, Y.; et al. A single-cell survey of the small intestinal epithelium. Nature 2017, 551, 333-339. [CrossRef] [PubMed]

42. Spanier, B.; Rohm, F. Proton Coupled Oligopeptide Transporter 1 (PepT1) Function, Regulation, and Influence on the Intestinal Homeostasis. Compr. Physiol. 2018, 8, 843-869. [CrossRef] [PubMed]

43. Lalles, J.P. Recent advances in intestinal alkaline phosphatase, inflammation, and nutrition. Nutr. Rev. 2019, 77, 710-724. [CrossRef] [PubMed]

44. Bilski, J.; Mazur-Bialy, A.; Wojcik, D.; Zahradnik-Bilska, J.; Brzozowski, B.; Magierowski, M.; Mach, T.; Magierowska, K.; Brzozowski, T. The Role of Intestinal Alkaline Phosphatase in Inflammatory Disorders of Gastrointestinal Tract. Mediat. Inflamm. 2017, 2017, 9074601. [CrossRef] [PubMed]

45. Braga Emidio, N.; Hoffmann, W.; Brierley, S.M.; Muttenthaler, M. Trefoil Factor Family: Unresolved Questions and Clinical Perspectives. Trends Biochem. Sci. 2019, 44, 387-390. [CrossRef] [PubMed]

46. Bergstrom, J.H.; Birchenough, G.M.; Katona, G.; Schroeder, B.O.; Schutte, A.; Ermund, A.; Johansson, M.E.; Hansson, G.C. Gram-positive bacteria are held at a distance in the colon mucus by the lectin-like protein ZG16. Proc. Natl. Acad. Sci. USA 2016, 113, 13833-13838. [CrossRef] [PubMed]

47. Wosen, J.E.; Mukhopadhyay, D.; Macaubas, C.; Mellins, E.D. Epithelial MHC Class II Expression and Its Role in Antigen Presentation in the Gastrointestinal and Respiratory Tracts. Front. Immunol. 2018, 9, 2144. [CrossRef]

48. Biton, M.; Haber, A.L.; Rogel, N.; Burgin, G.; Beyaz, S.; Schnell, A.; Ashenberg, O.; Su, C.W.; Smillie, C.; Shekhar, K.; et al. T Helper Cell Cytokines Modulate Intestinal Stem Cell Renewal and Differentiation. Cell 2018, 175, 1307-1320.e22. [CrossRef]

49. Demitrack, E.S.; Samuelson, L.C. Notch regulation of gastrointestinal stem cells. J. Physiol. 2016, 594, 4791-4803. [CrossRef]

50. Meng, D.; Frank, A.R.; Jewell, J.L. mTOR signaling in stem and progenitor cells. Development 2018, 145. [CrossRef]

51. Garcia-Hernandez, V.; Quiros, M.; Nusrat, A. Intestinal epithelial claudins: Expression and regulation in homeostasis and inflammation. Ann. New York Acad. Sci. 2017, 1397, 66-79. [CrossRef] [PubMed]

52. Laplante, M.; Sabatini, D.M. Regulation of mTORC1 and its impact on gene expression at a glance. J. Cell Sci. 2013, 126, 1713-1719. [CrossRef] [PubMed]

53. Ma, J.; Meng, Y.; Kwiatkowski, D.J.; Chen, X.; Peng, H.; Sun, Q.; Zha, X.; Wang, F.; Wang, Y.; Jing, Y.; et al. Mammalian target of rapamycin regulates murine and human cell differentiation through STAT3/p63/Jagged/Notch cascade. J. Clin. Investig. 2010, 120, 103-114. [CrossRef]

54. Poser, S.W.; Park, D.M.; Androutsellis-Theotokis, A. The STAT3-Ser/Hes3 signaling axis: An emerging regulator of endogenous regeneration and cancer growth. Front. Physiol. 2013, 4, 273. [CrossRef] [PubMed]

55. Pajvani, U.B.; Qiang, L.; Kangsamaksin, T.; Kitajewski, J.; Ginsberg, H.N.; Accili, D. Inhibition of Notch uncouples Akt activation from hepatic lipid accumulation by decreasing mTorc1 stability. Nat. Med. 2013, 19, 1054-1060. [CrossRef]

56. Shimobayashi, M.; Hall, M.N. Making new contacts: The mTOR network in metabolism and signalling crosstalk. Nat. Rev. Mol. Cell Biol. 2014, 15, 155-162. [CrossRef]

57. van Es, J.H.; van Gijn, M.E.; Riccio, O.; van den Born, M.; Vooijs, M.; Begthel, H.; Cozijnsen, M.; Robine, S.; Winton, D.J.; Radtke, F.; et al. Notch/gamma-secretase inhibition turns proliferative cells in intestinal crypts and adenomas into goblet cells. Nature 2005, 435, 959-963. [CrossRef]

58. Salas, A.; Hernandez-Rocha, C.; Duijvestein, M.; Faubion, W.; McGovern, D.; Vermeire, S.; Vetrano, S.; Vande Casteele, N. JAK-STAT pathway targeting for the treatment of inflammatory bowel disease. Nat. Rev. Gastroenterol. Hepatol. 2020, 17, 323-337. [CrossRef]

59. Rahner, C.; Mitic, L.L.; Anderson, J.M. Heterogeneity in expression and subcellular localization of claudins 2, 3, 4, and 5 in the rat liver, pancreas, and gut. Gastroenterology 2001, 120, 411-422. [CrossRef]

60. Beumer, J.; Clevers, H. Cell fate specification and differentiation in the adult mammalian intestine. Nat. Rev. Mol. Cell Biol. 2021, 22, 39-53. [CrossRef]

61. Danese, S.; Grisham, M.; Hodge, J.; Telliez, J.B. JAK inhibition using tofacitinib for inflammatory bowel disease treatment: A hub for multiple inflammatory cytokines. Am. J. Physiol. Gastrointest. Liver Physiol. 2016, 310, G155-G162. [CrossRef] [PubMed] 